\title{
The roles of protein expression in synaptic plasticity and memory consolidation
}

\section{Tali Rosenberg ${ }^{1}$, Shunit Gal-Ben-Ari ${ }^{1}$, Daniela C. Dieterich ${ }^{2,3,4}$, Michael R. Kreutz ${ }^{5}$, Noam E. Ziv ${ }^{6}$, Eckart D. Gundelfinger ${ }^{7,4,8}$ and Kobi Rosenblum ${ }^{1,9} *$}

Sagol Department of Neurobiology, University of Haifa, Haifa, Israel

2 Institute for Pharmacology and Toxicology, Otto-von-Guericke University, Magdeburg, Germany

${ }^{3}$ Research Group Neuralomics, Leibniz Institute for Neurobiology, Magdeburg, Germany

${ }^{4}$ Center for Behavioral Brain Sciences, Magdeburg, Germany

${ }^{5}$ Research Group Neuroplasticity, Leibniz Institute for Neurobiology, Magdeburg, Germany

${ }^{6}$ Network Biology Research Laboratories and Faculty of Medicine, Technion - Israel Institute of Technology, Haifa, Israel

7 Department of Neurochemistry and Molecular Biology, Leibniz Institute for Neurobiology, Magdeburg, Germany

${ }^{8}$ Medical School, Otto von Guericke University, Magdeburg, Germany

${ }^{9}$ Center for Gene Manipulation in the Brain, University of Haifa, Haifa, Israel

\section{Edited by:}

Nicola Maggio, The Chaim Sheba

Medical Center, Israel

\section{Reviewed by:}

Clive R. Bramham, University of Bergen, Norway

Andreas Vlachos, Goethe University

Frankfurt, Germany

\section{*Correspondence:}

Kobi Rosenblum, Sagol Department of Neurobiology, University of Haifa, 199 Aba Khoushi Avenue, Mount Carmel, Haifa 3498838, Israel e-mail:kobir@psy.haifa.ac.il
The amount and availability of proteins are regulated by their synthesis, degradation, and transport. These processes can specifically, locally, and temporally regulate a protein or a population of proteins, thus affecting numerous biological processes in health and disease states. Accordingly, malfunction in the processes of protein turnover and localization underlies different neuronal diseases. However, as early as a century ago, it was recognized that there is a specific need for normal macromolecular synthesis in a specific fragment of the learning process, memory consolidation, which takes place minutes to hours following acquisition. Memory consolidation is the process by which fragile short-term memory is converted into stable long-term memory. It is accepted today that synaptic plasticity is a cellular mechanism of learning and memory processes. Interestingly, similar molecular mechanisms subserve both memory and synaptic plasticity consolidation. In this review, we survey the current view on the connection between memory consolidation processes and proteostasis, i.e., maintaining the protein contents at the neuron and the synapse. In addition, we describe the technical obstacles and possible new methods to determine neuronal proteostasis of synaptic function and better explain the process of memory and synaptic plasticity consolidation.

Keywords: protein expression, translation regulation, synaptic stability, synapse, learning, memory consolidation

\section{INTRODUCTION}

Memory can be defined as storage of information manifested as changes over time in the physiology or behavior of an organism in response to environmental stimuli (Crystal and Glanzman, 2013). This definition encompasses not only multi-cellular organisms with evolved brains but also bacteria and plants (Song et al., 2013; Stock and Zhang, 2013). In this review we will focus on organisms in which memory processes are largely mediated by complex nervous systems. In such organisms, memories can be retained for seconds to years, with memory persistence strongly affected by the complexity of the organism's behavioral repertoire and nervous system, the attention paid to a given experience and the positive or negative value the organism assigns to it by way of interpretation. Indeed, experiences that are of consequence to the organism's survival, such as assessment of the safeness or toxicity of food, or experiences associated with pain, are learned quickly, and persist for long time periods - in many cases the life span of the organism (Johansen et al., 2011; Gal-Ben-Ari and Rosenblum, 2012).

In organisms with complex nervous systems, memory storage is believed to be heavily based on changes in synapses (Martin et al., 2000; Martin and Morris, 2002), specialized sites of cell-cell contact that connect the nerve cells within the nervous system. Although changes in synaptic connections, broadly referred to as synaptic plasticity, represent only one of multiple neuronal plasticity processes [which include, among others, changes in neuronal excitability, adult neurogenesis, and large scale changes in cortical maps (Giese and Mizuno, 2013)], synaptic plasticity has received the most attention. This attention is justified by the functional potency and enormous flexibility offered by changes at these strategic locations, ideas that can be traced back to the writings of James, Cajal, Freud, and most influentially, Hebb (Berlucchi and Buchtel, 2009; Schott, 2011).

As functionally appealing as these ideas are, nervous systems of all organisms are constrained by their underlying biology, and synapses are no exception. Synapses are composed of proteins, some of which play direct roles in synaptic transmission, whereas others regulate synaptic function or serve as structural scaffolds. Proteins, including synaptic ones, have finite lifetimes and, therefore, need to be continuously replaced with freshly synthesized copies. Moreover, functional changes in particular synapses call for changes in their proteinaceous contents in terms of amounts, distribution, and post-translational modifications. Both synaptic protein homeostasis (proteostasis), as well as functional changes 
in synaptic protein content present daunting challenges from the perspective of the neuron: the number of synapses is typically huge, their molecular makeup is extraordinarily complex, and their distance from the cell body, where most protein synthesis occurs, can be enormous, in comparison to the average size of a neuronal soma. The regulation of synaptic protein contents is further challenged by the requirement for high fidelity maintenance and trafficking processes essential to minimize spurious changes in synaptic properties, preserve changes induced by physiologically relevant signals, and introduce changes only when and where changes are called for. As a result, the ability of synapses to preserve their individual characteristics for long durations or to modify them in response to physiological stimuli is not obvious at all.

Generally speaking, biological processes mediating memory formation involve numerous tightly regulated molecular and cellular events. These include mRNA transcription; protein synthesis (mRNA translation); mRNA and protein degradation; mRNA and protein trafficking; post-translational modifications such as phosphorylation and ubiquitination; and epigenetic mechanisms, e.g., histone acetylation, DNA methylation, and miRNA regulation (Elkobi et al., 2008; Barki-Harrington et al., 2009; Belelovsky et al., 2009; Gal-Ben-Ari et al., 2012; Gildish et al., 2012; Giese and Mizuno, 2013; Graff and Tsai, 2013; Jarome and Helmstetter, 2013; Saab and Mansuy, 2014). Such processes can be brain hemisphere- and brain subregion-specific (Inberg et al., 2013; Chinnakkaruppan et al., 2014). In following with the term "consolidation" introduced by experimental psychologists (Lechner et al., 1999), the transfer from short-term memory (STM; minutes to hours) to long-term memory (LTM; days to a life time) during which a memory becomes less labile and sensitive to various types of physical or chemical disruption is termed "molecular memory consolidation” (McGaugh, 2000; Kandel, 2001; Dudai, 2004; Merhav and Rosenblum, 2008; Alberini, 2011). The duration of molecular memory consolidation, which varies among different behavioral paradigms and species, is biochemically defined by dependence on unperturbed protein synthesis in the relevant brain regions (Davis and Squire, 1984; Matthies, 1989a,b; Rosenblum et al., 1993; Meiri and Rosenblum, 1998; Costa-Mattioli et al., 2009). In contrast to LTM, STM is not dependent on protein translation (Houpt and Berlin, 1999).

The sensitivity of memory consolidation to manipulations that suppress protein synthesis has important parallels in the most widely studied experimental models of synaptic plasticity, namely long-term potentiation (LTP) and long-term depression (LTD). Synaptic changes induced by LTP and LTD are observable within seconds or minutes of their induction, but their persistence beyond a few hours seems to be strongly dependent on protein synthesis (Nguyen et al., 1994; Rosenblum et al., 2000) but see (Abbas et al., 2009; Villers et al., 2012). Such long-term changes in synaptic strength are usually referred to as "synaptic consolidation" (Clopath, 2012).

The large body of work on molecular and synaptic consolidation has collectively led to the view that long lasting phases of memory formation are dependent on regulated protein expression. Moreover, this body of work has given rise to several notable themes. The first distinguishes between post-translational modifications underlying STM and early phase LTP and a requirement for new protein synthesis for late phase LTP. The second concerns the existence of temporally restricted time windows during which protein synthesis inhibitors are capable of abolishing late phase LTP or the formation of long term memories. The third distinguishes between rapidly occurring processes based on protein synthesis (translation) and slower processes that invoke unique gene expression programs (transcription). The fourth concerns local (mainly dendritic) protein synthesis and processing that is based on organelles, such as polyribosomes located in the vicinity of synapses, and the fifth concerns the existence of specific molecules and pathways involved in synapse to nucleus communication, activated in response to requirements for "plasticity related" proteins at specific synapses. The common denominator of these themes is the view that LTP (and LTD), and by extension, learning processes, invoke fast (sub second) post translational modifications, followed by translation (global and local) and subsequent gene transcription programs (in the soma) with "plasticity proteins" synthesized in the process acting to consolidate changes at specific subsets of synapses.

Whereas this concept is appealing, there are many indications that it is extremely oversimplified. For example, (1) live imaging studies indicate that many synaptic proteins and organelles continuously move in, out, and between synapses (reviewed in Choquet and Triller, 2013; Ziv and Fisher-Lavie, 2014). How do synaptic protein synthesis and degradation rates compare to their exchange and interchange dynamics? How can synapses maintain their specific properties if their molecular constituents are continuously interchanged among nearby synapses? What are the relative contributions of protein redistribution and protein synthesis to synaptic plasticity? (2) To this day, it remains unclear if protein synthesis is required for the provision of "plasticity specific" proteins or simply for the replenishment of depleted components. Which proteins, if any, are synthesized specifically as part of molecular consolidation processes? Where are these synthesized? How long does it take to traffic them to remote synapses? How are they targeted to specific synapses? What prevents their interchange with nearby synapses once they arrive? (3) The conclusion that long lasting phases of memory formation are dependent on regulated protein expression strongly hinges on pharmacological agents that suppress protein synthesis. How do these agents affect ongoing activity in the intact brain (Sharma etal., 2012)? How does this concur with other findings indicating that the requirement for protein synthesis can be relieved by pharmacological agents that inhibit protein degradation (Fonseca et al., 2006a,b); how specific are the activities of these agents? (4) Synapse to nucleus communication is severely challenged by time and space constraints: How can the minute quantities of signaling molecules released from individual synapses overcome the vast distances from remote synapses to the soma?

In the current review, we will try to address some of these questions, using insights gained from our own work and from the work of many others, focusing, where possible, on general principles rather than detailed molecular descriptions and on issues that still remain open. While in recent years tight reciprocal relationships between neurons and astrocytes have been discovered and the now 
well recognized concept of the "Tripartite synapse" highlights the importance of glia cells for neuronal function and development (Hama et al., 2004; Elmariah et al., 2005), we will mainly focus on the neuronal part of the synapse. However, these general principles of protein homeostasis are likely to be applicable to both neurons and astrocytes.

\section{METABOLIC HALF LIFETIMES OF KEY SYNAPTIC PROTEINS}

As mentioned above, synaptic proteostasis presents daunting challenges from the perspective of the neuron. It thus stands to reason that metabolic turnover rates of synaptic proteins, i.e., their synthesis and degradation rates, would be relatively slow, to minimize the metabolic load of synaptic proteostasis, to allow long transport times along axons and dendrites, and to reduce the likelihood of inaccurate replacement events. In agreement with this reasoning, older studies based on radio-labeling methods indicated that turnover rates of some presynaptic proteins can be remarkably slow, resulting in half-lives (i.e., the time over which one-half of an initial protein quotient is degraded) of many days and even weeks (e.g., Baitinger and Willard, 1987; Petrucci et al., 1991). More recent studies based on synaptically enriched biochemical preparations (synaptosomes) and radioactive amino acids (typically methionine) have reported half-lives for pre- and postsynaptic scaffolding proteins in the range of several hours (e.g., Ehlers, 2003; Yao et al., 2007). In other studies, in which similar methods were used, much longer half-lives were reported for key synaptic proteins such as PSD-95 (El-Husseini et al., 2002) and the AMPA-type glutamate receptor subunit GluA2 (Kjoller and Diemer, 2000). Until recently, however, a systematic analysis of synaptic protein metabolic turnover kinetics was lacking.

The development of new methods for labeling newly synthesized proteins in cultured cells and in whole animals, combined with mass spectroscopy has allowed an unbiased, systematic measurement of turnover rates of thousands of proteins, including synaptic ones. These studies revealed that turnover rates of synaptic proteins are quite slow, with half-lives on the order of 2 to 5 days in cell culture (Cohen et al., 2013) and probably three to four times longer in adult mice (Price et al., 2010). Some examples of reported half-lives include (in hours, for cell culture/adult mice, respectively) the synaptic vesicle protein Synaptophysin: 98/502; the active zone Bassoon: 62/240; the AMPA type glutamate receptor subunit GluA2: 47/73; the postsynaptic density protein Dlg4 (PSD-95): 88/367; and the protein kinase CaMKII $\beta$ 2: 91/157 (see also Figure 1). Interestingly, bioinformatics-based analyses did not reveal significant differences between metabolic turnover rates among presynaptic proteins, postsynaptic proteins, and proteins whose mRNAs are consistently found in dendrites (Cohen et al., 2013). Similarities in turnover were found for some functionally or structurally related proteins (indicative, perhaps of coupled biogenesis, and degradation), but at the same time, proteins belonging to the same compartment could have very

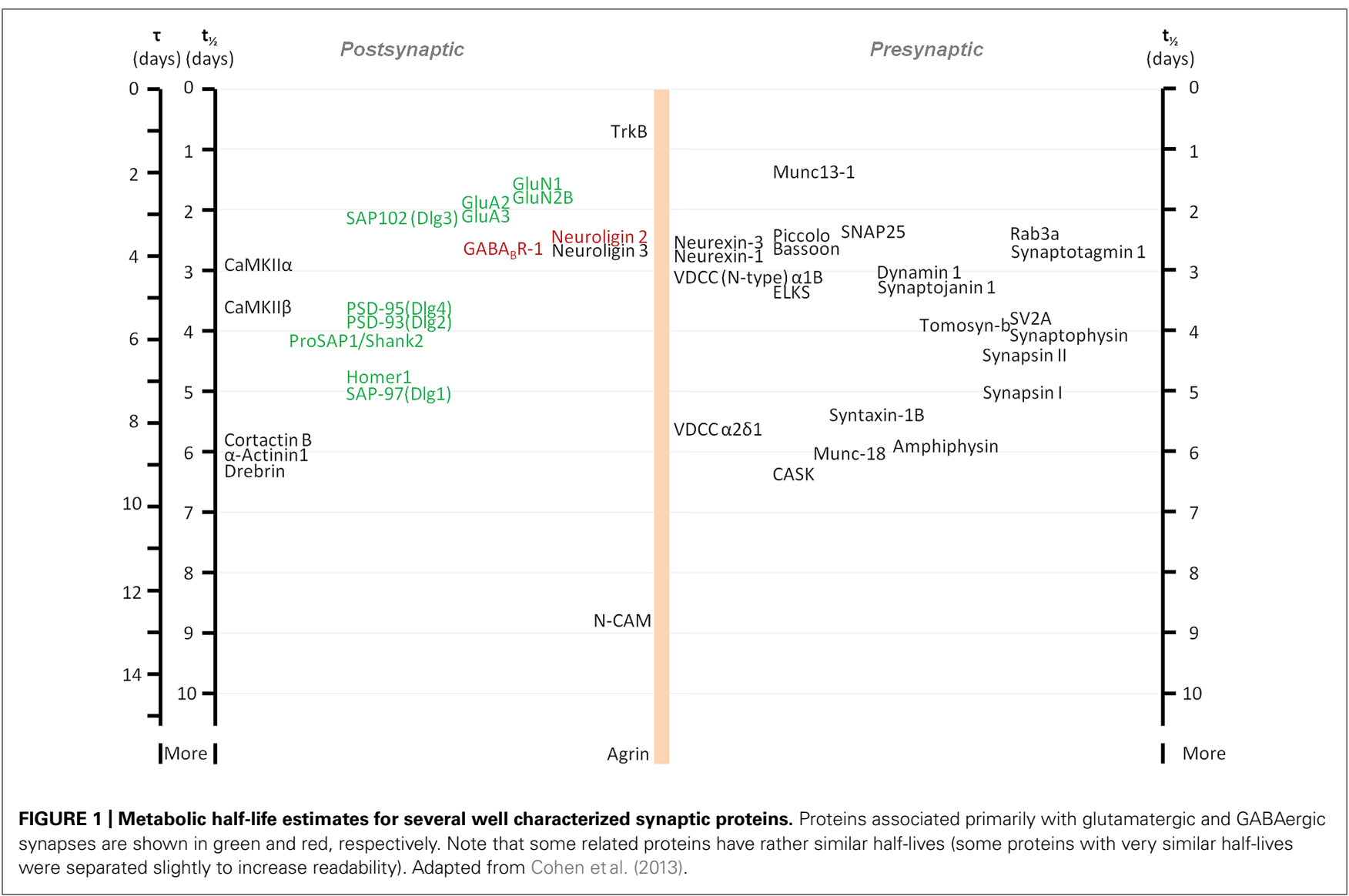


different half-lives (Cohen et al., 2013; Toyama et al., 2013). On the whole, the average turnover rate of synaptic proteins in culture was calculated to be on the order of about $0.7 \%$ per hour.

While protein synthesis and degradation are undoubtedly essential for synaptic proteostasis, it is important to stress that dynamics of synaptic proteins seem to be dominated by much faster processes, which do not involve the breakdown and synthesis of synaptic molecules, but rather their migration in, out, and between synapses. This conclusion is based on numerous live-imaging studies of multiple synaptic proteins, e.g., neurotransmitter receptors, scaffolding molecules, adhesion molecules, and even synaptic vesicles, which reveal typical residency times of seconds to minutes (receptors, cytoskeletal proteins) to several hours (core active zone and postsynaptic molecules). These studies collectively indicate that synapses are not so much structures in a strict sense, as much as dynamic molecular assemblies at complex steady states (Choquet and Triller, 2013; Ziv and FisherLavie, 2014). This state of things would seem to suggest that the availability of many synaptic proteins might not constitute a limiting factor when rapid changes in synapse composition and size are required, simply because synaptic components (such as vesicles; Darcy et al., 2006) and synaptic molecules could be recruited from nearby synapses (e.g., Krueger et al., 2003; Dobie and Craig, 2011; Mondin et al., 2011). Indeed, a recent detailed analysis of LTP-induced dendritic spine enlargement (Bosch et al., 2014) suggests that this holds true for actin and actin-binding proteins as well as glutamate receptors; on the other hand, the addition of core postsynaptic density proteins (Homer1b, Shank1b) and possibly postsynaptic density enlargement in general do not occur if protein synthesis is blocked, indicating that the de novo synthesis of key proteins might be required for synaptic consolidation.

Thus, on the whole, and in line with the a priori reasoning described above, the turnover of many synaptic proteins is relatively slow. Yet, it is also important to keep in mind that these estimates were largely based on mass spectroscopy systems, which are inherently biased toward the most prevalent proteins in protein mixtures, and are often blind to cell compartment-specific turnover rates. It thus remains entirely possible that the turnover rates of scarcer synaptic proteins, perhaps proteins that act locally to regulate important synaptic functions, are very different from those described above (see for example Waites et al., 2013). On the other hand, no technique is without shortcomings. Thus, for example, pulse-chase experiments based on radioactive methionine, the canonical method for measuring protein turnover, are typically associated with 100-fold reductions in extracellular concentrations of this essential amino acid. In yeast, similar reductions in extracellular methionine have been recently shown to trigger autophagy (Sutter et al., 2013), raising questions as to the accuracy of turnover rates estimated by this method. Newer methods, such as TimeSTAMP (Butko et al., 2012) are based on measuring degradation rates of fusion proteins (typically expressed under strong promoters), which might differ from those of endogenous forms. At present, therefore, it seems that there is still much uncertainty concerning the metabolic turnover of synaptic proteins and much to learn about how these might be affected by physiological and pathological conditions.

\section{THE INTERPLAY OF PROTEIN TRANSLATION AND DEGRADATION IN SYNAPTIC PLASTICITY AND CONSOLIDATION}

Protein degradation has emerged as one of the mechanisms necessary for memory consolidation (Lopez-Salon et al., 2001; Artinian et al., 2008; Jarome et al., 2011; Reis et al., 2013) and reconsolidation/extinction (Artinian et al., 2008; Lee et al., 2008, 2012), as has been shown using different behavioral paradigms (Jarome and Helmstetter, 2014). The balance between protein synthesis and protein degradation is important for synaptic plasticity, as inhibition of the proteasome or protein synthesis impairs late phase LTP, but co-inhibition of both proteasome activity and protein synthesis has no effect (Fonseca et al., 2006a). Along these lines, it has been shown that LTP increases the rate of protein synthesis, and enhances protein degradation via the ubiquitin-proteasome system (UPS; Fonseca et al., 2006b).

The significance of both protein synthesis and degradation for synaptic proteostasis is illustrated by fragile $\mathrm{X}$ syndrome, manifested by cognitive impairment and increase in dendritic protein translation (Sidorov et al., 2013). At the basis of this syndrome is the loss of fragile $\mathrm{X}$ mental retardation protein (FMRP). Phosphorylated FMRP has been shown to bind dendritic polyribosomes, thus stalling protein synthesis (Figure 2). FMRP

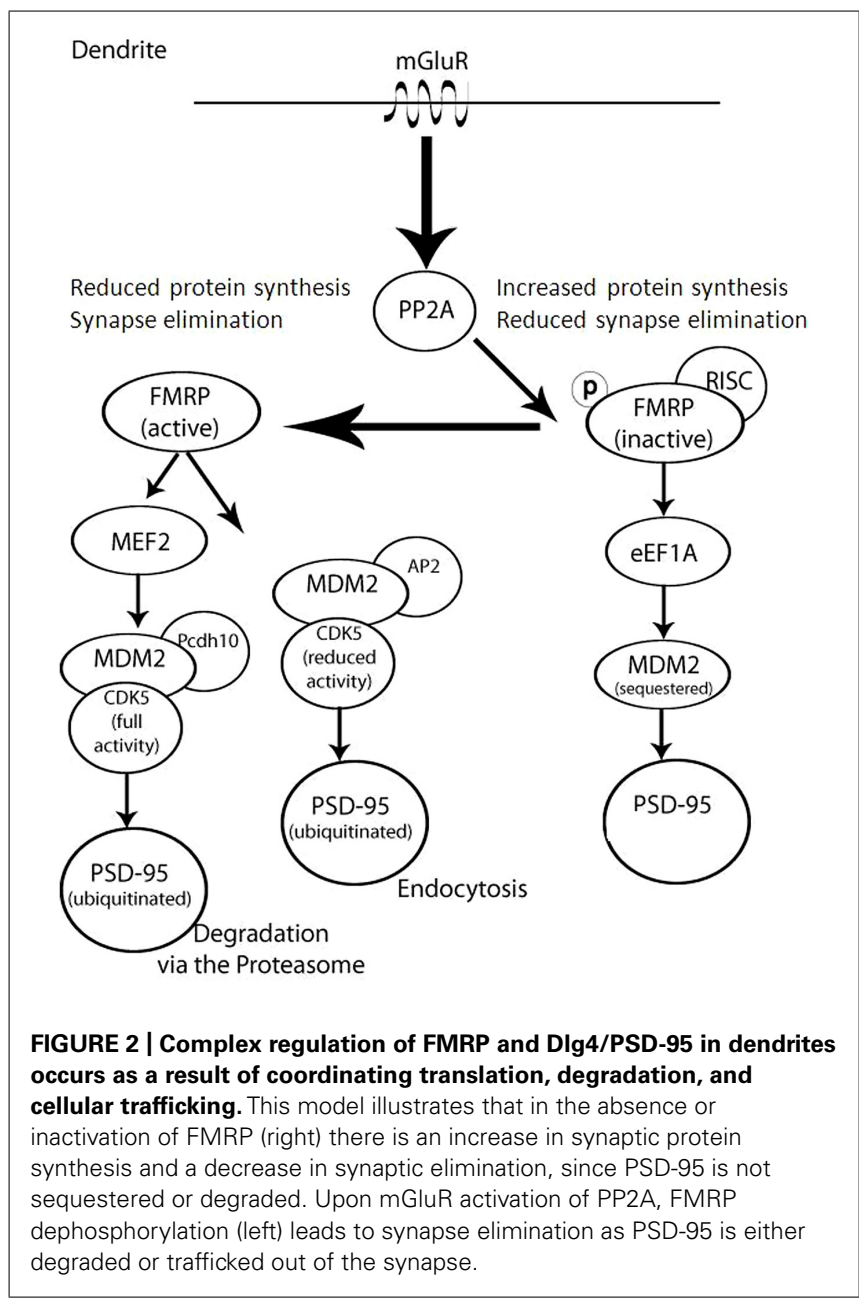


dephosphorylation by activated metabotropic glutamate receptors leads to the dissociation of FMRP from the stalled polyribosomes, thereby increasing rates of protein synthesis. FMRP dephosphorylation also promotes its degradation by the UPS (Nalavadi et al., 2012). Thus, FMRP dephosphorylation both activates translation and promotes the degradation of the protein that suppresses translation, presenting an example of tight coordination between protein translation and degradation.

While the UPS clearly plays essential roles in protein degradation, its involvement in the direct degradation of synaptic proteins is less straightforward. It has been reported several times that treatment with UPS inhibitors can lead to the loss (rather than accumulation) of synaptic proteins (e.g., Ding et al., 2006; Lazarevic et al., 2011; Bajic et al., 2012), possibly by promoting an unfolded protein response (UPR) and the consequential inhibition of protein synthesis (e.g., Ding et al., 2006; Zhang et al., 2010). One notable exception in this regard is the postsynaptic protein GKAP (guanylate kinase-associated protein, also known as SAPAP) which does seem to be directly degraded by the UPS (Ehlers, 2003; Shin et al., 2012). Interestingly, GKAP degradation does not seem to occur in situ, as its degradation seems to be preceded by trafficking to the cell body where it is ultimately destroyed.

As mentioned above, memory consolidation is defined as a post-acquisition period sensitive to interference. In many of these studies, this interference was induced experimentally by pharmacological agents that inhibit protein synthesis (Alberini, 2008). Various eukaryotic protein synthesis inhibitors are available, most of which attenuate translation elongation (Table 1). However, inhibition of protein synthesis may harbor detrimental effects: in some cases these inhibitors can cause DNA damage, teratogenesis, birth defects, muscle weakness, cardiotoxicity, immunosuppression, and apoptosis. In other cases protein synthesis inhibitors have

Table 1 | Protein synthesis inhibitors and their mechanism of action.

\begin{tabular}{|c|c|}
\hline $\begin{array}{l}\text { Protein synthesis } \\
\text { inhibitor }\end{array}$ & Action \\
\hline Anisomycin & 80s peptidyl transferase inhibitor Tang et al. (2012) \\
\hline Cycloheximide & $\begin{array}{l}\text { Inhibition of eEF2-mediated translocation Alberini } \\
\text { (2008) }\end{array}$ \\
\hline Diphtheria toxin & $\begin{array}{l}\text { Inhibits eEF2 by catalyzing ADP-ribosylation on a } \\
\text { diphthamide residue Su et al. (2013) }\end{array}$ \\
\hline $\begin{array}{l}\text { Emetine } \\
\text { dihydrochloride }\end{array}$ & Inhibition of translocation Alberini (2008) \\
\hline NSC11989 & $\begin{array}{l}\text { Preventing the formation of } 48 \text { s pre-initiation } \\
\text { complex Novac et al. (2004) }\end{array}$ \\
\hline Puromycin & $\begin{array}{l}\text { Amino-acyl tRNA analog, induces premature } \\
\text { termination Alberini (2008) }\end{array}$ \\
\hline Salubrinal & Inhibits elF2 $\alpha$ phosphatase Wu etal. (2014) \\
\hline 4EGl-1 & $\begin{array}{l}\text { Inhibition of elF4E-elF4G binding and } \\
\text { cap-dependent translation initiation Hoeffer et al. } \\
\text { (2011) }\end{array}$ \\
\hline
\end{tabular}

antitumor effects (Tang et al., 2012). Finally, it has been suggested that these inhibitors can rapidly and acutely suppress spontaneous activity levels (Sharma etal., 2012). For the study of protein degradation, several proteasome inhibitors have been developed (Table 2). Here too, however, inhibition of the proteasome may cause cytotoxic effects, lead to apoptosis (Goldberg, 2012), or induce an UPR and a consequential suppression of protein synthesis (Ding et al., 2006; Bajic et al., 2012).

Research employing general tools as inhibitors of protein synthesis and the UPS is inherently limited in its ability to enable detailed elucidation of the interaction between protein synthesis and degradation during synaptic plasticity and learning and memory. Therefore, the next level should be studies focused on specific translation regulation factors and their interaction with the degradation machinery. For example, proteasome inhibition-induced enhanced L-LTP is attenuated by interfering with the interaction between eukaryotic initiation factors eIF4E and eIF4G in the hippocampus (Dong et al., 2008, 2014). Blocking of the interaction between eIF4E and eIF4G in the amygdala attenuates long term fear memory consolidation (Hoeffer et al., 2011). Moreover, proteasome inhibition is associated with an increase in expression levels of eIF4E and eukaryotic elongation factor eEF1A (Dong et al., 2008, 2014).

While eEF1A transports aminoacyl tRNAs into the ribosome during translation elongation, its isoform eEF1A2 interacts with newly synthesized proteins (NSPs) and promotes their proteasomal degradation. NSP degradation is increased during stress, following c-Jun $N$-terminal kinase (JNK) phosphorylation of eEF1A2 on Ser205 and Ser358 (Gandin et al., 2013). Translation elongation is also regulated by the phosphorylation of eukaryotic elongation factor 2 (eEF2) and its kinase, eEF2 kinase (Pavitt and Proud, 2009), degraded by the specific E3 ubiquitin ligase SCFßTRCP (Wiseman et al., 2013).

Eukaryotic initiation factor $2 \alpha(\mathrm{eIF} 2 \alpha)$ phosphorylation is increased during aging and neurodegenerative disorders including Alzheimer's disease and related cognitive impairments (Segev et al., 2013; Ohno, 2014). Heterozygous replacement of eIF2 $\alpha$ Ser51 to Ala results in an increase in L-LTP and improved cognitive performance (Costa-Mattioli etal., 2007). One of the kinases regulating eIF2 $\alpha$, protein kinase RNA-like endoplasmic reticulum kinase (PERK), plays an important role in cortical-dependent memory consolidation (Ounallah-Saad et al., 2014). PERK induces an UPR following ER stress, and promotes cell survival via activation of NF-E2-related factor 2 (Nrf2). Nrf2 is a transcription factor activating genes encoding for detoxifying enzymes [e.g., $\mathrm{NAD}(\mathrm{P}) \mathrm{H}$ : quinone oxidoreductase 1 (Nqo1)], but also for the human catalytic proteasome subunit PSMB5 (Cullinan etal., 2003; Lee et al., 2012). Proteasome inhibition may induce prolonged ER stress, and eventually cause apoptosis (Woehlbier and Hetz, 2011), further increased when combined with salubrinal, an inhibitor of the eIF2 $\alpha$ s phosphatase, PP1 (Schewe and Aguirre-Ghiso, 2009).

Interestingly, some components of the cellular protein synthesis machinery are homologous to components of the degradation machinery. For example, human eIF3, which participates in the recruitment of the ribosomal 40s subunit and the formation of 
Table 2 | Proteasome inhibitors and their mechanism of action.

\begin{tabular}{|c|c|}
\hline Proteasome inhibitor & Action \\
\hline Bortezomib and MG-132 & $\begin{array}{l}\text { Reversible inhibition of chymotrypsin-like activity of the } 20 \text { s subunit and caspase-like activity at higher concentrations. } \\
\text { Bortezomib is } 50 \text { to } 100 \text {-fold more potent than MG-132 Goldberg (2012) }\end{array}$ \\
\hline Lactacystin & $\begin{array}{l}\text { Binding to the catalytic core of the } 20 \text { s subunit, inhibiting all three catalytic activities. Irreversible and fast inhibition of the } \\
\text { trypsin and chymotrypsin like catalytic activities Craiu et al. (1997) }\end{array}$ \\
\hline Lactacystin clasto- $\beta$ lactone & The active form of lactacystin Craiu et al. (1997) \\
\hline Epoxomycin & $\begin{array}{l}\text { Binding to the catalytic core of the } 20 \text { s subunit, inhibiting all three catalytic activities, with higher affinity to the } \\
\text { chymotrypsin like catalytic activity Kim and Crews (2013) }\end{array}$ \\
\hline
\end{tabular}

the pre-initiation complex (Sha et al., 2009), consists of 13 different subunits containing domains which are homologous to the 19s proteasome regulatory particle. Among these is Rpn6, which stabilizes the connection between the 19 s regulatory particle and the 20s core particle. Rpn6 shows homology to eIF3 subunits a and $c$, which participate in the recruitment of the 40s subunit to the ternary complex, but also to subunits e and 1 (Scheel and Hofmann, 2005; Suo et al., 2011; Pathare et al., 2012). In addition, eIF3e depletion in human mammary epithelium decreases ubiquitin levels as well as functional proteasomes (Suo et al., 2011).

In this part we reviewed some examples how protein translation and UPS-dependent degradation cross-regulate each other. Since tagging with ubiquitin (or ubiquitin-like) moieties can promote various cellular processes in addition to degradation, including cellular signaling as well as protein trafficking, activity, and localization, we assume that an interplay of these processes controls the proteostasis effect on synaptic plasticity and learning processes.

\section{CHANGES IN THE SYNAPTIC PROTEOME ASSOCIATED WITH PLASTICITY AND MEMORY PROCESSES}

The sensitivity of molecular and synaptic consolidation processes to treatments that suppress protein synthesis implies that these processes depend on the availability of NSPs, but their identity remains elusive. It is not even clear if the NSPs are (i) "plasticityspecific" proteins that lead to qualitative changes in the synaptic proteome, or (ii) a manifestation of quantitative changes needed for synaptic growth, or metabolic housekeeping and maintenance, for example.

The search for memory-associated changes in the synaptic proteome is not new, and the results of such searches have been continuously refined by the development of new and more sensitive techniques. Thus, for example, quantitative and qualitative changes in protein expression associated with long-term facilitation in Aplysia sensory neurons were studied using twodimensional gels, resulting in the identification of about 10 individual proteins whose expression levels changed over the course of these experiments (Barzilai et al., 1989). Similarly, significant changes in the protein composition of synaptic junctions following processes of high (pathological) synaptic activity have been reported more than a decade ago (Hu et al., 1998; Wyneken et al., 2001) using micro-sequencing and immunoblots. Since then, mass spectrometry and proteomic methods have been used to characterize the contents of synaptic protein preparations [for review see: (Sheng and Hoogenraad, 2007), in exquisite detail (Chua et al., 2010; Pielot et al., 2012), http://www.synprot.de/], and to follow changes in the proteome in various brain regions in response to memory-relevant plasticity processes. However, most of these studies analyzed changes in whole cell/tissue extracts and, therefore, could only indirectly infer alterations of the synaptic proteome (e.g., McNair et al., 2006, 2007; Monopoli et al., 2011; Hong et al., 2013).

Here, we consider some recent studies that focused on protein fractions enriched for synaptic protein components. An interesting study by Trinidad et al. (2013) reported global activity-dependent changes in the murine synaptic proteome after massive activity onset utilizing the pilocarpine model of epilepsy. They followed the regulation of more than a 100 core protein components of the postsynaptic density that were defined based on previous studies (Sheng and Hoogenraad, 2007; Fernandez et al., 2009) during the first hour after pilocarpine application, assuming that this time window covers mainly the phase of redistribution between synapse-associated and cytoplasmic protein pools. During this initial phase of activity-induced synaptic reorganization, the authors found a relatively tight dynamic co-regulation of a cluster of proteins around $\alpha$-Amino-3-hydroxy-5-methyl-4-isoxazolepropionic acid (AMPA)- and N-methyl-D-aspartate (NMDA)-type glutamate receptors and their scaffolding proteins. Interestingly, isoforms of $\mathrm{Ca}^{2+} /$ calmodulin-dependent protein kinase type II (CaMKII) displayed a relative down-regulation (10-20\% decrease) $60 \mathrm{~min}$ after pilocarpin stimulation. The downscaling of this highly abundant protein at the excitatory postsynapse (Kelly et al., 1984) could be indicative of subsequent restructuring processes of synaptic junctions (see also Bosch et al., 2014; Meyer et al., 2014).

A recent study on synaptic proteome changes in response to aversively motivated complex auditory learning revealed a surprisingly strong relative down-regulation of synaptic protein components six and $24 \mathrm{~h}$ after shuttle box training in four different regions of the mouse brain, i.e., auditory cortex, prefrontal cortex, striatum, and hippocampus (Kahne et al., 2012). Unrelated tone and mild foot-shock stimuli had significantly smaller effects. Down-regulated elements include, among others, large scaffolds on both sides of the synaptic junctions as well as trafficking molecules or components of the UPS. These observations 
suggest that learning-related plasticity processes as a first step may induce the removal and/or degradation of proteins from both the presynaptic cytomatrix at the active zone and the postsynaptic density, and thereby loosen or 'deconstruct' the synaptic structures and prepare them for reconstruction (echoing similar ideas in older studies, e.g., Lynch and Baudry, 1984). Redondo and Morris (Redondo et al., 2010) proposed that this kind of "permissive unlocking" of synaptic structures might be part of the synaptic tagging mechanism (Bosch et al., 2014; Meyer et al., 2014). One of the signaling pathways inducing this unlocking process seems to involve insulin or insulin-like growth factors (Kahne et al., 2012) - factors that have been implicated in a variety of memory processes (Alberini and Chen, 2012). Altogether, these findings suggest that multiple interacting processes (as indicated in Figure 3) control the protein levels in the synapse during learning and memory-dependent synaptic plasticity.
Recent developments toward the selective analysis of distinct synaptic subtypes such as the Fluorescence Activated Synaptosome Sorting (FASS) method (Biesemann et al., 2014) or by concentrating on the pool of NSPs using non-canonical amino acids (Dieterich et al., 2006, 2007) may result in a more detailed and focused picture of synaptic proteome alterations during synaptic plasticity events. With bioorthogonal non-canonical amino acid tagging (BONCAT; Hodas et al., 2012) recently were able to identify the dopaminergic subproteome in rat hippocampal neuropil. Interestingly, many of the candidate proteins identified in the dopamine agonist-treated sample belong to gene ontology (GO) categories specific for protein synthesis and synaptic function. In the same study the authors visualized using fluorescent non-canonical amino acid tagging (FUNCAT; Dieterich et al., 2010) an increase in protein synthesis, especially in more distal dendritic regions in dopamine agonist-treated neurons

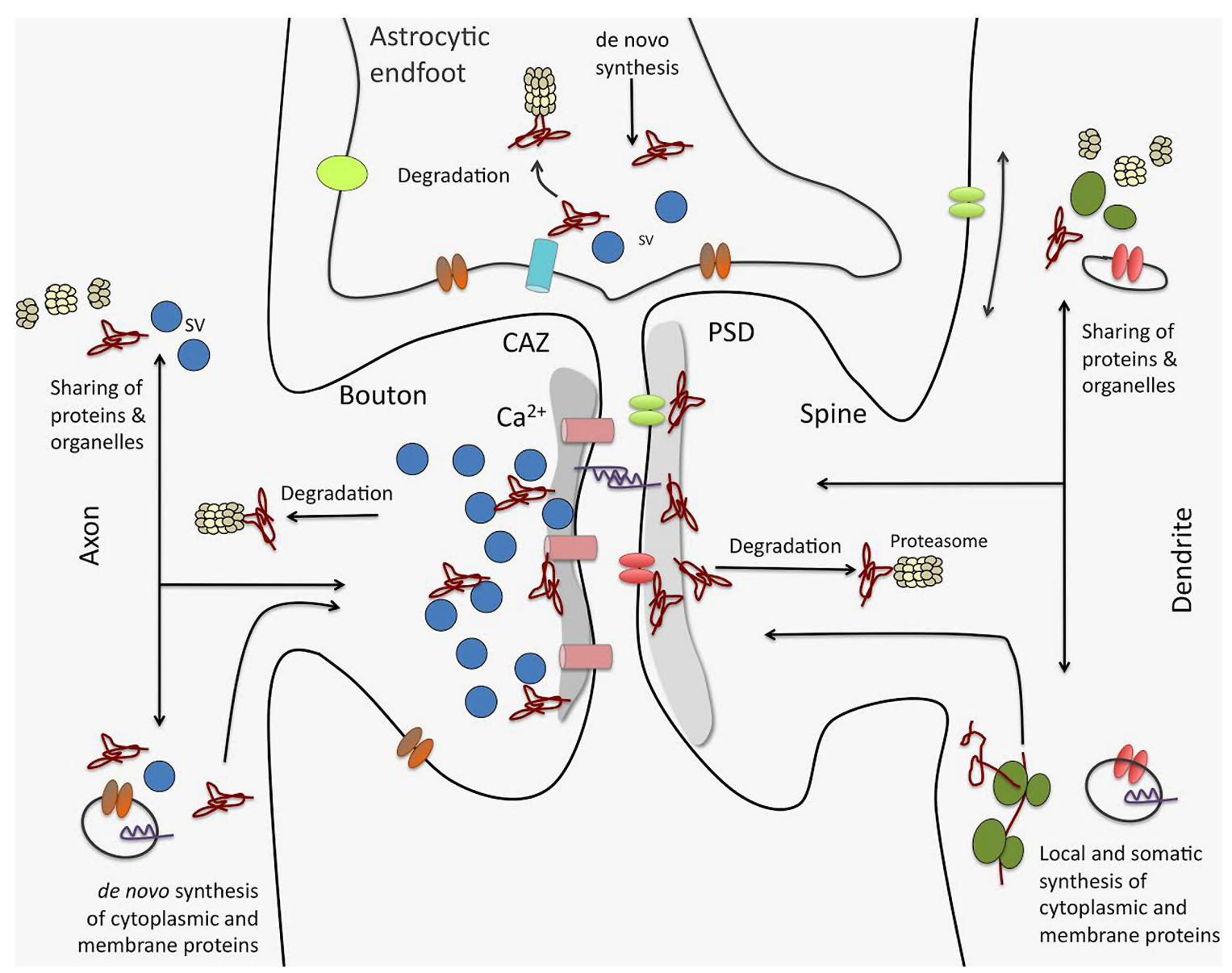

FIGURE 3 | Processes driving synaptic proteome changes upon memory formation and consolidation. Mainly three processes acting on both sides of the synapse as well as in astrocytic endfeet intimately contacting synaptic junctions control the turnover of the synaptic protein machinery: (i) de novo synthesis of cytoplasmic and membrane proteins that may take place locally or in remote compartments, such as the neuronal soma. This includes both translation by ribosomes as well as complex cellular sorting pathways. (ii) protein degradation, e.g., by the ubiquitin proteasome system, but also by lysosomal and autophagic processes (not shown). And (iii) competitive sharing of proteins, molecular machines (e.g., proteasomes, ribosomes), and organelles between synapses seems to be an important factor in regulating the protein equipment of individual synapses. Sharing of proteins and organelles can occur via intracellular transport processes as well as via diffusion in the cell membrane. Interactive regulation of these processes for protein assemblies and individual proteins is thought to determine protein composition in synapses and thereby govern their individual functionality, and in turn, their contribution to neuronal networks. CAZ, cytomatrix at the active zone; PSD, postsynaptic density; SV, synaptic vesicle. 
further providing evidence that different cellular compartments may have different needs, in terms of quantity and quality, for NSPs upon synaptic plasticity. By combining both cell-selectivity (such as the FASS methodology) and the selective analysis of NSPs, one might be able to improve our current knowledge of memory-associated changes in the synaptic proteome by identifying even subtle memory-related cell-specific changes in synaptic protein composition. These changes include also alterations in the protein content of, e.g., astrocytic endfeet tightly connected to the presynaptic and postsynaptic sites of synapses (see also Figure 3).

\section{TRAFFICKING OF NEWLY SYNTHESIZED PROTEINS TO SYNAPSES}

As mentioned in the introduction, the delivery and removal of proteins to and from synapses is of critical importance for both maintaining and changing synaptic function, yet this necessity is challenged by the huge number of synaptic connections neurons make and receive, the polarized architecture of neurons, the presence of long and branched dendrites and their extraordinarily elongated and extensively bifurcated axonal arbors. Generally speaking, these challenges have been addressed by (1) the development of sophisticated and quite efficient transport mechanisms for delivering particular proteins to the far reaches of the cell and (2) the development of distributed protein synthesis facilities in dendrites and possibly in axons as well (see, e.g., Holt and Schuman, 2013).

While protein synthesis can occur in dendrites and axons (as discussed below), it is generally thought that most synaptic proteins, and in particular presynaptic proteins, are transported from the cell body (e.g., Lee and Hollenbeck, 2003). An intricate transport and processing system mediates proper trafficking and localization of proteins synthesized in the cell body to the synapse and to the extracellular space. During synthesis of proteins in the soma, axonal, and dendritic synaptic proteins are sorted into distinct (dendritic or axonal) vesicles at the trans-Golgi membrane owing to distinct sorting peptide motifs, binding to adaptor protein complexes such as AP-4, and other regulatory proteins (Matsuda et al., 2008). Movement of vesicles along microtubule and actin filaments depends on these scaffolding and adaptor proteins that are recognized by molecular motors including kinesins and dyneins (Hirokawa, 1998; Vale, 2003).

Molecular motors involved in transport are sensitive to the polarity of cytoskeletal filaments along which they translocate. Microtubule polarity in dendrites depends on proximity to the cell body: in proximal dendrites microtubule polarity is mixed, whereas in distal dendrites microtubules have a plus-orientation toward the distal tips. In contrast, axonal microtubules are organized uniformly with their plus end toward the distal tips of axons (Baas et al., 1988). Anterograde axonal and dendritic transport of NSPs is mediated by kinesin motors, whereas myosin VI, a minusend directed motor on actin filaments, is crucially involved in regulating concentrations of axonal proteins (Lewis et al., 2011). Interestingly, vesicles carrying dendritic transmembrane proteins undergo trafficking only within somatodendritic compartments (Burack et al., 2000; Silverman et al., 2001). Recently, the axon initial segment was found to act as a vesicle filter mediating differential trafficking of dendritic and axonal transport vesicles (Al-Bassam et al., 2012). Although vesicles targeted to dendrites entered axons and dendrites with equal proportions, they halted or reversed direction in the axon initial segment in an actin and myosin Va-dependent manner.

The aforementioned, relatively efficient trafficking mechanisms apply mainly to vesicular cargos (as well as mitochondria) and to proteins that (transiently) associate with such cargos. Many other proteins, including synaptic proteins, are trafficked to remote sites by mechanisms collectively referred to as slow axonal transport. As the name implies, trafficking rates can be rather slow, on the order of a few millimeters per day (Hoffman and Lasek, 1975; Vallee and Bloom, 1991; Scott et al., 2011). In fact, when live imaging methods were used to measure the rates at which an axonal protein, e.g., Synapsin (Tsuriel et al., 2006; Tang et al., 2013) or a dendritic protein, e.g., ProSAP2/Shank3 (Tsuriel et al., 2006) were trafficked from the cell body to remote synapses, it was found that their accumulation at remote synapses occurred over many hours and days. These slow trafficking rates pose yet another challenge, as they imply that synaptic proteins must be protected from significant degradation en route. Otherwise, sufficient amounts of important synaptic proteins would never reach their remote destinations (a conundrum raised by Alvarez et al., 2000).

The logistic challenges posed by long-range trafficking are partially addressed by the presence of distributed, local facilities for protein synthesis and processing in dendrites and possibly in axons (Holt and Schuman, 2013). In this non-canonical mode of protein synthesis, proteins are synthesized locally by polysomes located in close proximity to synaptic sites. There is increasing evidence that local dendritic protein synthesis allows individual synapses to respond dynamically to the environmental changes that drive the establishment, maintenance, and plasticity of synaptic connections. The same is true for local axonal protein synthesis, which occurs in growing axons to exert axon guidance as well as in mature axons to maintain, for instance, axonal stability and integrity (Jung et al., 2012; Yoon et al., 2012, for a recent review). It is worth noting, however, that while such local protein synthesis systems are usually discussed in the context of synaptic plasticity, perhaps their primary role is to maintain the proteinaceous contents of synapses in face of the logistic challenges associated with longrange protein transport from the remote cell body (Alvarez et al., 2000).

The canonical route by which integral membrane (and secreted) proteins are synthesized, modified, and delivered consists of transport through several membrane-bound structures, including the endoplasmic reticulum (ER), the ER-Golgi intermediate compartment, the Golgi apparatus, the trans-Golgi network and vesiculotubular carriers. This raises the question as to how proteins synthesized in remote sites are processed and delivered to the plasma membrane. Golgi outposts have been localized in dendrites (but so far not in axons), concentrating at branch points, where they can participate in post-Golgi trafficking of vesicles (Horton and Ehlers, 2003; Horton et al., 2005), as well as potentially in trafficking and maturation of dendritically synthesized proteins (reviewed in Hanus and Schuman, 2013). But how can selective targeting of NSPs to a subset of modified synapses be achieved with a continuous somatodendritic ER? The 
ER contributes to various forms of synaptic plasticity through $\mathrm{Ca}^{2+}$ release, but also via ER-formed organelles (spine apparatus organelle) composed of stacked smooth ER, which are found in dendritic spines (Spacek and Harris, 1997). The spine apparatus is known to enter and leave, change position and size in a subset of spines (Maggio and Vlachos, 2014). The position and size of the spine apparatus is thought to affect $\mathrm{Ca}^{2+}$ homeostasis in the spine compartment, thereby influencing the ability of individual synapses to undergo plasticity. However, further studies are necessary to elucidate the detailed mechanism underlying this effect. Selective targeting of NSPs to a subset of modified synapses is also achieved by microtubule-dependent transport of vesicles. Notably, vesicles carrying different receptors, such as NMDA and AMPA receptors, can be sorted into distinct pools taking different routes to the plasma membrane. While AMPA receptors take the canonical secretory pathway through the somatic ER and Golgi network, NMDAR-carrying vesicles bypass the somatic Golgi and directly merge with Golgi outposts, depending on the adaptor proteins CASK and SAP97 (Jeyifous etal., 2009). Moreover, Cui-Wang et al. (2012) have previously shown an increased ER complexity at branch points and in the proximity of synaptic spines, which could facilitate protein export and processing at secretory hubs in dendrites. Here, AMPARs were shown to rapidly diffuse within the continuous somatodendritic ER, but were restricted in their movement at sites of extensive ER complexity.

It thus seems that in dendrites, the presence of a plethora of mRNAs (Cajigas et al., 2012), polyribosomes, translation factors, regulatory proteins, and Golgi outposts enables the synthesis of a diverse array of different protein classes including receptors, scaffolding, and signaling molecules, thereby bypassing long-distance trafficking of proteins. Many membrane and secreted proteins, however, are highly glycosylated, and indeed, the glycosylation pattern can serve to distinguish mature from immature proteins. Taking into account the low abundance of Golgi outposts in dendrites (Hanus and Ehlers, 2008), NSPs might not undergo all of the processing steps of the canonical secretory pathway, and therefore, could be functionally different from somatically synthesized ones. Thus, faster and more accurate delivery might be at the expense of functional maturity and protein stability.

At present, the relative fractions of somatic or locally synthesized proteins needed for the initial assembly of synapses, their maintenance and their modification remains unknown. We expect that new methods and approaches, such as those mentioned above, will gradually clarify these matters.

\section{THE IMPACT OF LONG DISTANCE TRANSPORT OF SYNAPTIC PROTEINS TO THE NUCLEUS ON SYNAPTIC FUNCTION AND MEMORY CONSOLIDATION}

Several studies have provided compelling evidence that activitydependent gene transcription plays an important role in preserving changes in synaptic strength as well as in LTM formation (West and Greenberg, 2011). Apart from fast $\mathrm{Ca}^{2+}$ signals that elicit immediate early gene expression on a time scale of minutes (Saha and Dudek, 2013), the long-distance transport of proteins from the synapse to the nucleus has attracted considerable interest in recent years (Jordan and Kreutz, 2009; Karpova et al., 2012; Kaushik et al.,
2014). This type of signaling is conceptually appealing because it allows for local encoding of signals at the site of origin and decoding in the nucleus. Yet many questions, factual and conceptual remain: How do synapses differentiate between ongoing synaptic activation and specific activity patterns that drive synapse to nucleus communication? What is the nature of such communication molecules? How do the presumably minute quantities of signaling molecules released from a small number of remote synapses overcome the vast distances from and to the soma? How do they retain their integrity and specific properties along the way?

Recent work has indeed shown that distinct signaling events like activation of synaptic vs. extrasynaptic NMDA receptors (Karpova etal., 2013) or activation of different synaptic kinase and phosphatase pathways (Ch'ng et al., 2012) are encoded locally by phosphorylation of messenger molecules that then transit to the nucleus. Other studies uncovered mechanisms which preserve phosphorylation signals during retrograde transport to the nucleus (Karpova et al., 2013). According to this model, synaptic proteins dock at their target sites following nuclear import, and elicit a genomic response that depends on phosphorylation of crucial phospho-sites (Karpova et al., 2013).

A good example for this type of signaling is the synaptonuclear messenger protein, Jacob, which enters the nucleus following activation of GluN2B-containing NMDAR at synaptic and extrasynaptic sites. The information thought to be encoded and transduced by Jacob pertains to the origin of NMDAR signals to the nucleus: whether it is synaptic or extrasynaptic (Karpova et al., 2013). Synaptic NMDAR activate ERK, and active ERK then binds to Jacob and phosphorylates a crucial serine at position 180 . A stable trimeric complex with proteolytically cleaved c-terminal fragments of the neurofilament $\alpha$-internexin is then formed, which protects serine 180 phosphorylation and active ERK against phosphatase activity during transport. Zhai et al. (2013) have recently shown that following the induction of LTP in just a few spines, nuclear ERK activity increases with a delay of $30 \mathrm{~min}$. This activation is independent of voltage-dependent calcium channels and membrane depolarization, and it is tempting to speculate that Jacob might bind active ERK and bring it to the nucleus. Nuclear trafficking requires binding to neuronal importins at synapses and in dendrites (Dieterich et al., 2008), which in turn provide an adaptor for association to a dynein motor. Jacob transits to the nucleus via an active retrograde transport along microtubules. Following nuclear entry, Jacob docks a NMDAR-derived signalosome, that might arguably differ between synaptic and extrasynaptic receptors with different consequences for gene expression, to nuclear target sites (Karpova et al., 2013).

A limited number of target interactions, the stability of protein complexes, and their presumably prolonged effect on transcriptional regulation may confer specificity and efficiency to messengers like Jacob. Furthermore, following nuclear import from the synapse, nucleo-cyotplasmic shuttling and the nuclear residing time can be tightly regulated by subsequent neuronal activity as recently shown for CRTC-1 (Ch'ng et al., 2012). What are the molecular underpinnings of such a signaling mechanism? It is well established that NMDARs are crucially involved in learning and memory and play a pivotal role in synapse-to-nucleus 
communication in pyramidal neurons of the hippocampus. The NMDAR complex is a particularly rich source of synapto-nuclear messengers (Karpova et al., 2012) and it is plausible that the assembly of the transport complex starts in close proximity to NMDARs. A splice isoform of the GluN1 subunit of NMDARs harbors a classic nuclear localization signal sequence (NLS) to which importin- $\alpha$ can be docked (Jeffrey et al., 2009). This interaction is modulated by protein kinase $\mathrm{C}(\mathrm{PKC})$, which phosphorylates the NLS region of GluN1 in an activity-dependent manner, making importin$\alpha 1$ available for nuclear trafficking (Jeffrey et al., 2009). Neuronal importins are present in dendrites and synapses from where they can translocate to the nucleus following NMDAR activation (Thompson et al., 2004; Dieterich et al., 2008), and importin- $\alpha$ can associate with a dynein motor for retrograde transport to the nucleus (Hanz et al., 2003).

A yet unresolved issue is how the transport complex is assembled and how NMDAR signals induce dissociation of these messengers from the synapse. Published evidence suggests that different signals can induce the nuclear import of different synapto-nuclear protein messengers. The transcription factor cAMP response element-binding protein 2 (CREB2), for instance, only translocates from synapse to nucleus after the induction of NMDAR-dependent LTD, but not LTP (Lai et al., 2008). In contrast, Jacob only transits to the nucleus following induction of Schaffer collateral NMDAR LTP but not LTD at CA1 synapses (Behnisch et al., 2011).

Interestingly, the nuclear action of many messengers like CRTC1 and Jacob are related to transcriptional co-activation and repression of CREB (Ch'ng et al., 2012; Karpova et al., 2013). This may reflect the central function of CREB in plasticity mechanisms like LTP and its role in the formation of long-term memories. On the other hand, a systematic analysis of gene expression induced by such signaling mechanisms is still pending. At present it is largely unclear how activity-induced gene expression as such feeds back to synaptic function. It will be challenging to identify the cellular mechanisms for protein transport from synapse-tonucleus and trafficking of NSPs back to synapses. Additionally, the role of these processes in memory formation merits further investigation.

\section{TECHNOLOGICAL OBSTACLES AND OUTLOOK}

Before concluding, we wish to state the obvious, that advances in our understanding of the subject matter have been made possible by the development of novel methods, but have also been hampered by the inherent limitations of these same methods. Thus, for example, FUNCAT allows for the visualization of NSPs but does not resolve the identity of the NSPs. Methods based on metabolic labeling and mass spectroscopy, such as stable isotope labeling with amino acids in cell culture (SILAC) and MS (for a recent review see Hoedt et al., 2014) have provided unprecedented information on the turnover rates of major neuronal proteins, yet they tend to "miss" less abundant proteins, have poor temporal resolution and practically no spatial resolution. Genetic methods, such as TimeSTAMP (Butko et al., 2012) allow for the visualization of newly synthesized copies of particular proteins and for measurements of their degradations rates, but the physiological relevance of these data are sensitive to the degree to which the regulation of expression as well as the degradation rates of these exogenous fusion proteins mimic those of their endogenous counterparts. This is not to say that many of these impediments will not be overcome. Thus, for example, combining BONCAT with SILAC has given rise to QuaNCAT, which has allowed for quantifying changes in the synthesis of $>600$ proteins in primary $\mathrm{T}$ cells following activating stimuli (Howden et al., 2013). New methods for controlling the translation of particular mRNA transcripts (Cao et al., 2013) or driving the degradation of particular proteins (Renicke et al., 2013) by means of light have been described. New technologies with greater sensitivities, resolving power, and improved spatiotemporal resolution are certain to appear and will, in all likelihood, extend our understanding of relationships between protein metabolism, synaptic stability, and plasticity.

\section{SUMMARY}

At present, the literature contains a huge number of studies concerning relationships between protein metabolism, synaptic maintenance and synaptic consolidation on the one hand, and various memory consolidation processes on the other. The interpretation of the latter in the context of the former has often been confounded by a lack of basic information on key issues, such as the lifetime of neuronal proteins, the dynamics of protein trafficking, the nature of synapse to nucleus communication, the source, repertoire, and amounts of NSPs, their modulation by behavioral, physiological (and non-physiological) manipulations, the actual roles and targets of protein degradation systems, and the full scope of reactions invoked by pharmacological manipulations of protein metabolism. Over the last years, with the development of new techniques and approaches, significant progress has been made. Nevertheless, much is yet to be learned on these and other basic issues if we hope to understand the principles that tie together synaptic protein metabolism, synaptic biology, memory formation, and memory consolidation.

\section{AUTHOR CONTRIBUTIONS}

Tali Rosenberg, Shunit Gal-Ben-Ari, Daniela C. Dieterich, Michael R. Kreutz, Noam E. Ziv, Eckart D. Gundelfinger, and Kobi Rosenblum have contributed equally to this work.

\section{ACKNOWLEDGMENTS}

This work was supported by the DFG German-Israeli Foundation DIP (RO3971/1-1) for Kobi Rosenblum, Noam E. Ziv and DFG/DIP (GU230/6) for Eckart D. Gundelfinger, Daniela C. Dieterich, Michael R. Kreutz; DFG SFB779 for Eckart D. Gundelfinger, Daniela C. Dieterich, Michael R. Kreutz; DFG (DI1512/1-1) for Daniela C. Dieterich; the European Union Seventh Framework Program EUROSPIN (Contract HEALTH F22009-241498) for Kobi Rosenblum and Noam E. Ziv; DFG Kr1879 (5-1) to Michael R. Kreutz; the Allen and Jewel Prince Center for Neurodegenerative Disorders of the Brain (NEZ); and the Wolfson charitable trust for Kobi Rosenblum.

\section{REFERENCES}

Abbas, A. K., Dozmorov, M., Li, R., Huang, F. S., Hellberg, F., Danielson, J., et al. (2009). Persistent LTP without triggered protein synthesis. Neurosci. Res. 63, 59-65. doi: 10.1016/j.neures.2008.10.008 
Al-Bassam, S., Xu, M., Wandless, T. J., and Arnold, D. B. (2012). Differential trafficking of transport vesicles contributes to the localization of dendritic proteins. Cell Rep. 2, 89-100. doi: 10.1016/j.celrep.2012.05.018

Alberini, C. M. (2008). The role of protein synthesis during the labile phases of memory: revisiting the skepticism. Neurobiol. Learn. Mem. 89, 234-246. doi: 10.1016/j.nlm.2007.08.007

Alberini, C. M. (2011). The role of reconsolidation and the dynamic process of long-term memory formation and storage. Front. Behav. Neurosci. 5:1-10. doi: 10.3389/fnbeh.2011.00012

Alberini, C. M., and Chen, D. Y. (2012). Memory enhancement: consolidation, reconsolidation and insulin-like growth factor 2. Trends Neurosci. 35, 274-283. doi: 10.1016/j.tins.2011.12.007

Alvarez, J., Giuditta, A., and Koenig, E. (2000). Protein synthesis in axons and terminals: significance for maintenance, plasticity and regulation of phenotype. With a critique of slow transport theory. Prog. Neurobiol. 62, 1-62. doi: 10.1016/S0301-0082(99)00062-3

Artinian, J., McGauran, A. M., De Jaeger, X., Mouledous, L., Frances, B., and Roullet P. (2008). Protein degradation, as with protein synthesis, is required during not only long-term spatial memory consolidation but also reconsolidation. Eur. J. Neurosci. 27, 3009-3019. doi: 10.1111/j.1460-9568.2008.06262.x

Baas, P. W., Deitch, J. S., Black, M. M., and Banker, G. A. (1988). Polarity orientation of microtubules in hippocampal neurons: uniformity in the axon and nonuniformity in the dendrite. Proc. Natl. Acad. Sci. U.S.A. 85, 8335-8339. doi: 10.1073/pnas.85.21.8335

Baitinger, C., and Willard, M. (1987). Axonal transport of synapsin I-like proteins in rabbit retinal ganglion cells. J. Neurosci. 7, 3723-3735.

Bajic, N., Jenner, P., Ballard, C. G., and Francis, P. T. (2012). Proteasome inhibition leads to early loss of synaptic proteins in neuronal culture. J. Neural Transm. 119 1467-1476. doi: 10.1007/s00702-012-0816-9

Barki-Harrington, L., Elkobi, A., Tzabary, T., and Rosenblum, K. (2009). Tyrosine phosphorylation of the $2 \mathrm{~B}$ subunit of the NMDA receptor is necessary for taste memory formation. J. Neurosci. 29, 9219-9226. doi: 10.1523/JNEUROSCI.566708.2009

Barzilai, A., Kennedy, T. E., Sweatt, J. D., and Kandel, E. R. (1989). 5-HT modulates protein synthesis and the expression of specific proteins during long-term facilitation in Aplysia sensory neurons. Neuron 2, 1577-1586. doi: 10.1016/0896-6273(89)90046-9

Behnisch, T., Yuanxiang, P., Bethge, P., Parvez, S., Chen, Y., Yu, J., et al. (2011). Nuclear translocation of jacob in hippocampal neurons after stimuli inducing long-term potentiation but not long-term depression. PLOS ONE 6:e17276. doi: 10.1371/journal.pone.0017276

Belelovsky, K., Kaphzan, H., Elkobi, A., and Rosenblum, K. (2009). Biphasic activation of the mTOR pathway in the gustatory cortex is correlated with and necessary for taste learning. J. Neurosci. 29, 7424-7431. doi: 10.1523/JNEUROSCI.380908.2009

Berlucchi, G., and Buchtel, H. A. (2009). Neuronal plasticity: historical roots and evolution of meaning. Exp. Brain Res. 192, 307-319. doi: 10.1007/s00221-0081611-6

Biesemann, C., Gronborg, M., Luquet, E., Wichert, S. P., Bernard, V., Bungers, S. R., et al. (2014). Proteomic screening of glutamatergic mouse brain synaptosomes isolated by fluorescence activated sorting. EMBO J. 33, 157-170. doi: 10.1002/embj. 201386120

Bosch, M., Castro, J., Saneyoshi, T., Matsuno, H., Sur, M., and Hayashi, Y. (2014). Structural and molecular remodeling of dendritic spine substructures during long-term potentiation. Neuron 82, 444-459. doi: 10.1016/j.neuron.2014. 03.021

Burack, M. A., Silverman, M. A., and Banker, G. (2000). The role of selective transport in neuronal protein sorting. Neuron 26, 465-472. doi: 10.1016/S08966273(00)81178-2

Butko, M. T., Yang, J., Geng, Y., Kim, H. J., Jeon, N. L., Shu, X., et al. (2012). Fluorescent and photo-oxidizing TimeSTAMP tags track protein fates in light and electron microscopy. Nat. Neurosci. 15, 1742-1751. doi: 10.1038/nn.3246

Cajigas, I. J., Tushev, G., Will, T. J., Tom Dieck, S., Fuerst, N., and Schuman, E. M. (2012). The local transcriptome in the synaptic neuropil revealed by deep sequencing and high-resolution imaging. Neuron 74, 453-466. doi: 10.1016/j.neuron.2012.02.036

Cao, J., Arha, M., Sudrik, C., Bugaj, L. J., Schaffer, D. V., and Kane, R. S. (2013). Light-inducible activation of target mRNA translation in mammalian cells. Chem. Commun. 49, 8338-8340. doi: 10.1039/c3cc44866e
Chinnakkaruppan, A., Wintzer, M. E., McHugh, T. J., and Rosenblum, K. (2014) Differential contribution of hippocampal subfields to components of associative taste learning. J. Neurosci. 34, 11007-11015. doi: 10.1523/JNEUROSCI.095614.2014

Ch'ng, T. H., Uzgil, B., Lin, P., Avliyakulov, N. K., O’Dell, T. J., and Martin, K. C. (2012). Activity-dependent transport of the transcriptional coactivator CRTC1 from synapse to nucleus. Cell 150, 207-221. doi: 10.1016/j.cell.2012.05.027

Choquet, D., and Triller, A. (2013). The dynamic synapse. Neuron 80, 691-703. doi: 10.1016/j.neuron.2013.10.013

Chua, J. J., Kindler, S., Boyken, J., and Jahn, R. (2010). The architecture of an excitatory synapse. J. Cell. Sci. 123, 819-823. doi: 10.1242/jcs.052696

Clopath, C. (2012). Synaptic consolidation: an approach to long-term learning Cogn. Neurodyn. 6, 251-257. doi: 10.1007/s11571-011-9177-6

Cohen, L. D., Zuchman, R., Sorokina, O., Muller, A., Dieterich, D. C., Armstrong, J. D., et al. (2013). Metabolic turnover of synaptic proteins: kinetics, interdependencies and implications for synaptic maintenance. PLoS ONE 8:e63191. doi: 10.1371/journal.pone.0063191

Costa-Mattioli, M., Gobert, D., Stern, E., Gamache, K., Colina, R., Cuello, C., et al. (2007). eIF $2 \alpha$ phosphorylation bidirectionally regulates the switch from short- to long-term synaptic plasticity and memory. Cell 129, 195-206. doi: 10.1016/j.cell.2007.01.050

Costa-Mattioli, M., Sossin, W. S., Klann, E., and Sonenberg, N. (2009). Translational control of long-lasting synaptic plasticity and memory. Neuron 61, 10-26. doi: 10.1016/j.neuron.2008.10.055

Craiu, A., Gaczynska, M., Akopian, T., Gramm, C. F., Fenteany, G., Goldberg A. L., et al. (1997). Lactacystin and clasto-lactacystin $\beta$-lactone modify multiple proteasome $\beta$-subunits and inhibit intracellular protein degradation and major histocompatibility complex class I antigen presentation. J. Biol. Chem. 272, 13437-13445. doi: 10.1074/jbc.272.20.13437

Crystal, J. D., and Glanzman, D. L. (2013). A biological perspective on memory. Curr. Biol. 23, R728-R731. doi: 10.1016/j.cub.2013.07.082

Cui-Wang, T., Hanus, C., Cui, T., Helton, T., Bourne, J., Watson, D., et al. (2012). Local zones of endoplasmic reticulum complexity confine cargo in neuronal dendrites. Cell 148, 309-321. doi: 10.1016/j.cell.2011.11.056

Cullinan, S. B., Zhang, D., Hannink, M., Arvisais, E., Kaufman, R. J., and Diehl, J. A. (2003). Nrf2 is a direct PERK substrate and effector of PERK-dependent cell survival. Mol. Cell. Biol. 23, 7198-7209. doi: 10.1128/MCB.23.20.7198-7209.2003

Darcy, K. J., Staras, K., Collinson, L. M., and Goda, Y. (2006). Constitutive sharing of recycling synaptic vesicles between presynaptic boutons. Nat. Neurosci. 9, 315-321. doi: 10.1038/nn1640

Davis, H. P., and Squire, L. R. (1984). Protein synthesis and memory: a review. Psychol. Bull. 96, 518-559. doi: 10.1037/0033-2909.96.3.518

Dieterich, D. C., Hodas, J. J., Gouzer, G., Shadrin, I. Y., Ngo, J. T., Triller, A., et al. (2010). In situ visualization and dynamics of newly synthesized proteins in rat hippocampal neurons. Nat. Neurosci. 13, 897-905. doi: 10.1038/nn.2580

Dieterich, D. C., Karpova, A., Mikhaylova, M., Zdobnova, I., Konig, I., Landwehr, M., et al. (2008). Caldendrin-Jacob: a protein liaison that couples NMDA receptor signalling to the nucleus. PLoS Biol. 6:e34. doi: 10.1371/journal.pbio.0060034

Dieterich, D. C., Lee, J. J., Link, A. J., Graumann, J., Tirrell, D. A., and Schuman, E. M. (2007). Labeling, detection and identification of newly synthesized proteomes with bioorthogonal non-canonical amino-acid tagging. Nat. Protoc. 2, 532-540. doi: 10.1038/nprot.2007.52

Dieterich, D. C., Link, A. J., Graumann, J., Tirrell, D. A., and Schuman, E. M. (2006). Selective identification of newly synthesized proteins in mammalian cells using bioorthogonal noncanonical amino acid tagging (BONCAT). Proc. Natl. Acad. Sci. U.S.A. 103, 9482-9487. doi: 10.1073/pnas.0601637103

Ding, Q., Dimayuga, E., Markesbery, W. R., and Keller, J. N. (2006). Proteasome inhibition induces reversible impairments in protein synthesis. FASEB J. 20, 1055-1063. doi: 10.1096/fj.05-5495com

Dobie, F. A., and Craig, A. M. (2011). Inhibitory synapse dynamics: coordinated presynaptic and postsynaptic mobility and the major contribution of recycled vesicles to new synapse formation. J. Neurosci. 31, 10481-10493. doi: 10.1523/JNEUROSCI.6023-10.2011

Dong, C., Bach, S. V., Haynes, K. A., and Hegde, A. N. (2014). Proteasome modulates positive and negative translational regulators in long-term synaptic plasticity. J. Neurosci. 34, 3171-3182. doi: 10.1523/JNEUROSCI.3291-13.2014

Dong, C., Upadhya, S. C., Ding, L., Smith, T. K., and Hegde, A. N. (2008). Proteasome inhibition enhances the induction and impairs the maintenance of late-phase long-term potentiation. Learn. Mem. 15, 335-347. doi: 10.1101/lm.984508 
Dudai, Y. (2004). The neurobiology of consolidations, or, how stable is the engram? Annu. Rev. Psychol. 55, 51-86. doi: 10.1146/annurev.psych.55.090902.142050

Ehlers, M. D. (2003). Activity level controls postsynaptic composition and signaling via the ubiquitin-proteasome system. Nat. Neurosci. 6, 231-242. doi: 10.1038/nn1013

El-Husseini, A., Schnell, E., Dakoji, S., Sweeney, N., Zhou, Q., Prange, O., et al. (2002). Synaptic strength regulated by palmitate cycling on PSD-95. Cell 108, 849-863. doi: 10.1016/S0092-8674(02)00683-9

Elkobi, A., Ehrlich, I., Belelovsky, K., Barki-Harrington, L., and Rosenblum, K. (2008). ERK-dependent PSD-95 induction in the gustatory cortex is necessary for taste learning, but not retrieval. Nat. Neurosci. 11, 1149-1151. doi: $10.1038 / \mathrm{nn} .2190$

Elmariah, S. B., Oh, E. J., Hughes, E. G., and Balice-Gordon, R. J. (2005). Astrocytes regulate inhibitory synapse formation via Trk-mediated modulation of postsynaptic GABAA receptors. J. Neurosci. 25, 3638-3650. doi 10.1523/JNEUROSCI.3980-04.2005

Fernandez, E., Collins, M. O., Uren, R. T., Kopanitsa, M. V., Komiyama, N. H., Croning, M. D., et al. (2009). Targeted tandem affinity purification of PSD-95 recovers core postsynaptic complexes and schizophrenia susceptibility proteins. Mol. Syst. Biol. 5, 269. doi: 10.1038/msb.2009.27

Fonseca, R., Vabulas, R. M., Hartl, F. U., Bonhoeffer, T., and Nägerl, U. V. (2006a). A balance of protein synthesis and proteasome-dependent degradation determines the maintenance of LTP. Neuron 52, 239. doi: 10.1016/j.neuron.2006.08.015

Fonseca, R., Nagerl, U. V., and Bonhoeffer, T. (2006b). Neuronal activity determines the protein synthesis dependence of long-term potentiation. Nat. Neurosci. 9, 478-480. doi: 10.1038/nn1667

Gal-Ben-Ari, S., Kenney, J. W., Ounalla-Saad, H., Taha, E., David, O., Levitan, D., et al. (2012). Consolidation and translation regulation. Learn. Mem. 19, 410-422. doi: $10.1101 / \mathrm{lm} .026849 .112$

Gal-Ben-Ari, S., and Rosenblum, K. (2012). Molecular mechanisms underlying memory consolidation of taste information in the cortex. Front. Behav. Neurosci. 5:87. doi: 10.3389/fnbeh.2011.00087

Gandin, V., Gutierrez, G. J., Brill, L. M., Varsano, T., Feng, Y., Aza-Blanc, P., et al. (2013). Degradation of newly synthesized polypeptides by ribosome-associated RACK1/c-Jun $\mathrm{N}$-terminal kinase/eukaryotic elongation factor 1A2 complex. Mol. Cell. Biol. 33, 2510-2526. doi: 10.1128/MCB.01362-12

Giese, K. P., and Mizuno, K. (2013). The roles of protein kinases in learning and memory. Learn. Mem. 20, 540-552. doi: 10.1101/lm.028449.112

Gildish, I., Manor, D., David, O., Sharma, V., Williams, D., Agarwala, U., et al. (2012). Impaired associative taste learning and abnormal brain activation in kinasedefective eEF2K mice. Learn. Mem. 19, 116-125. doi: 10.1101/1m.023937.111

Goldberg, A. L. (2012). Development of proteasome inhibitors as research tools and cancer drugs. J. Cell Biol. 199, 583-588. doi: 10.1083/jcb.201210077

Graff, J., and Tsai, L. H. (2013). Histone acetylation: molecular mnemonics on the chromatin. Nat. Rev. Neurosci. 14, 97-111. doi: 10.1038/nrn3427

Hama, H., Hara, C., Yamaguchi, K., and Miyawaki, A. (2004). PKC signaling mediates global enhancement of excitatory synaptogenesis in neurons triggered by local contact with astrocytes. Neuron 41, 405-415. doi: 10.1016/S0896-6273(04)0 0007-8

Hanus, C., and Ehlers, M. D. (2008). Secretory outposts for the local processing of membrane cargo in neuronal dendrites. Traffic 9, 1437-1445. doi: 10.1111/j.16000854.2008.00775.x

Hanus, C., and Schuman, E. M. (2013). Proteostasis in complex dendrites. Nat. Rev. Neurosci. 14, 638-648. doi: 10.1038/nrn3546

Hanz, S., Perlson, E., Willis, D., Zheng, J. Q., Massarwa, R., Huerta, J. J., et al. (2003). Axoplasmic importins enable retrograde injury signaling in lesioned nerve. Neuron 40, 1095-1104. doi: 10.1016/S0896-6273(03)00770-0

Hirokawa, N. (1998). Kinesin and dynein superfamily proteins and the mechanism of organelle transport. Science 279, 519-526. doi: 10.1126/science.279.5350.519

Hodas, J. J., Nehring, A., Hoche, N., Sweredoski, M. J., Pielot, R., Hess, S., et al. (2012). Dopaminergic modulation of the hippocampal neuropil proteome identified by bioorthogonal noncanonical amino acid tagging (BONCAT). Proteomics 12, 2464-2476. doi: 10.1002/pmic.201200112

Hoedt, E., Zhang, G., and Neubert, T. A. (2014). Stable isotope labeling by amino acids in cell culture (SILAC) for quantitative proteomics. Adv. Exp. Med. Biol. 806, 93-106. doi: 10.1007/978-3-319-06068-2_5

Hoeffer, C. A., Cowansage, K. K., Arnold, E. C., Banko, J. L., Moerke, N. J., Rodriguez, R., et al. (2011). Inhibition of the interactions between eukaryotic initiation factors $4 \mathrm{E}$ and $4 \mathrm{G}$ impairs long-term associative memory consolidation but not reconsolidation. Proc. Natl. Acad. Sci. U.S.A. 108, 3383-3388. doi: 10.1073/pnas.1013063108

Hoffman, P. N., and Lasek, R. J. (1975). The slow component of axonal transport. Identification of major structural polypeptides of the axon and their generality among mammalian neurons. J. Cell Biol. 66, 351-366. doi: 10.1083/jcb.66.2.351

Holt, C. E., and Schuman, E. M. (2013). The central dogma decentralized: new perspectives on RNA function and local translation in neurons. Neuron 80, 648657. doi: 10.1016/j.neuron.2013.10.036

Hong, I., Kang, T., Yun, K. N., Yoo, Y., Park, S., Kim, J., et al. (2013). Quantitative proteomics of auditory fear conditioning. Biochem. Biophys. Res. Commun. 434, 87-94. doi: 10.1016/j.bbrc.2013.03.060

Horton, A. C., and Ehlers, M. D. (2003). Dual modes of endoplasmic reticulumto-Golgi transport in dendrites revealed by live-cell imaging. J. Neurosci. 23, 6188-6199.

Horton, A. C., Racz, B., Monson, E. E., Lin, A. L., Weinberg, R. J., Ehlers, M. D. (2005). Polarized secretory trafficking directs cargo for asymmetric dendrite growth and morphogenesis. Neuron 48, 757-771. doi: 10.1016/j.neuron.2005.11.005

Houpt, T. A., and Berlin, R. (1999). Rapid, labile, and protein synthesis-independent short-term memory in conditioned taste aversion. Learn. Mem. 6, 37-46.

Howden, A. J., Geoghegan, V., Katsch, K., Efstathiou, G., Bhushan, B., Boutureira, O., et al. (2013). QuaNCAT: quantitating proteome dynamics in primary cells. Nat. Methods 10, 343-346. doi: 10.1038/nmeth.2401

Hu, B. R., Park, M., Martone, M. E., Fischer, W. H., Ellisman, M. H., and Zivin, J. A. (1998). Assembly of proteins to postsynaptic densities after transient cerebral ischemia. J. Neurosci. 18, 625-633.

Inberg, S., Elkobi, A., Edri, E., and Rosenblum, K. (2013). Taste familiarity is inversely correlated with Arc/Arg3.1 hemispheric lateralization. J. Neurosci. 33, 11734-11743. doi: 10.1523/JNEUROSCI.0801-13.2013

Jarome, T. J., and Helmstetter, F. J. (2013). The ubiquitin-proteasome system as a critical regulator of synaptic plasticity and long-term memory formation. Neurobiol. Learn. Mem. 105, 107-116. doi: 10.1016/j.nlm.2013.03.009

Jarome, T. J., and Helmstetter, F. J. (2014). Protein degradation and protein synthesis in long-term memory formation. Front. Mol. Neurosci. 7:61. doi: $10.3389 /$ fnmol.2014.00061

Jarome, T. J., Werner, C. T., Kwapis, J. L., and Helmstetter, F. J. (2011). Activity dependent protein degradation is critical for the formation and stability of fear memory in the amygdala. PLoS ONE 6:e24349. doi: 10.1371/journal.pone.0024349

Jeffrey, R. A., Ch'ng, T. H., O’Dell, T. J., and Martin, K. C. (2009). Activity-dependent anchoring of importin alpha at the synapse involves regulated binding to the cytoplasmic tail of the NR1-1a subunit of the NMDA receptor. J. Neurosci. 29, 15613-15620. doi: 10.1523/JNEUROSCI.3314-09.2009

Jeyifous, O., Waites, C. L., Specht, C. G., Fujisawa, S., Schubert, M., Lin, E. I., et al. (2009). SAP97 and CASK mediate sorting of NMDA receptors through a previously unknown secretory pathway. Nat. Neurosci. 12, 1011-1019. doi: $10.1038 / \mathrm{nn} .2362$

Johansen, J. P., Cain, C. K., Ostroff, L. E., and LeDoux, J. E. (2011). Molecular mechanisms of fear learning and memory. Cell 147, 509-524. doi: 10.1016/j.cell.2011.10.009

Jordan, B. A., and Kreutz, M. R. (2009). Nucleocytoplasmic protein shuttling: the direct route in synapse-to-nucleus signaling. Trends Neurosci. 32, 392-401. doi: 10.1016/j.tins.2009.04.001

Jung, H., Yoon, B. C., and Holt, C. E. (2012). Axonal mRNA localization and local protein synthesis in nervous system assembly, maintenance and repair. Nat. Rev. Neurosci. 13, 308-324. doi: 10.1038/nrn3274

Kahne, T., Kolodziej, A., Smalla, K. H., Eisenschmidt, E., Haus, U. U., Weismantel, R., et al. (2012). Synaptic proteome changes in mouse brain regions upon auditory discrimination learning. Proteomics 12, 2433-2444. doi: 10.1002/pmic.2011 00669

Kandel, E. R. (2001). The molecular biology of memory storage: a dialogue between genes and synapses. Science 294, 1030-1038. doi: 10.1126/science.1067020

Karpova, A., Bar, J., and Kreutz, M. R. (2012). Long-distance signaling from synapse to nucleus via protein messengers. Adv. Exp. Med. Biol. 970, 355-376. doi: 10.1007/978-3-7091-0932-8_16

Karpova, A., Mikhaylova, M., Bera, S., Bar, J., Reddy, P. P., Behnisch, T., et al. (2013). Encoding and transducing the synaptic or extrasynaptic origin of NMDA receptor signals to the nucleus. Cell 152, 1119-1133. doi: 10.1016/j.cell.2013.02.002 
Kaushik, R., Grochowska, K. M., Butnaru, I., and Kreutz, M. R. (2014). Protein trafficking from synapse to nucleus in control of activity-dependent gene expression. Neuroscience 280, 340-350. doi: 10.1016/j.neuroscience.2014.09.011

Kelly, P. T., McGuinness, T. L., and Greengard, P. (1984). Evidence that the major postsynaptic density protein is a component of a $\mathrm{Ca}^{2+} /$ calmodulindependent protein kinase. Proc. Natl. Acad. Sci. U.S.A. 81, 945-949. doi: 10.1073/pnas.81.3.945

Kim, K. B., and Crews, C. M. (2013). From epoxomicin to carfilzomib: chemistry, biology, and medical outcomes. Nat. Prod. Rep. 30, 600-604. doi: $10.1039 / \mathrm{c} 3 \mathrm{np} 20126 \mathrm{k}$

Kjoller, C., and Diemer, N. H. (2000). GluR2 protein synthesis and metabolism in rat hippocampus following transient ischemia and ischemic tolerance induction. Neurochem. Int. 37, 7-15. doi: 10.1016/S0197-0186(00)00008-5

Krueger, S. R., Kolar, A., and Fitzsimonds, R. M. (2003). The presynaptic release apparatus is functional in the absence of dendritic contact and highly mobile within isolated axons. Neuron 40, 945-957. doi: 10.1016/S0896-6273(03)00729-3

Lai, K. O., Zhao, Y., Ch'ng, T. H., and Martin, K. C. (2008). Importin-mediated retrograde transport of CREB2 from distal processes to the nucleus in neurons. Proc. Natl. Acad. Sci. U.S.A. 105, 17175-17180. doi: 10.1073/pnas.0803906105

Lazarevic, V., Schone, C., Heine, M., Gundelfinger, E. D., and Fejtova, A. (2011). Extensive remodeling of the presynaptic cytomatrix upon homeostatic adaptation to network activity silencing. J. Neurosci. 31, 10189-10200. doi: 10.1523/JNEUROSCI.2088-11.2011

Lechner, H. A., Squire, L. R., and Byrne, J. H. (1999). 100 years of consolidationremembering Muller and Pilzecker. Learn. Mem. 6, 77-87.

Lee, S. H., Choi, J. H., Lee, N., Lee, H. R., Kim, J. I., Yu, N. K., et al. (2008). Synaptic protein degradation underlies destabilization of retrieved fear memory. Science 319, 1253. doi: 10.1126/science. 1150541

Lee, S. H., Kwak, C., Shim, J., Kim, J. E., Choi, S. L., Kim, H. F., et al. (2012). A cellular model of memory reconsolidation involves reactivation-induced destabilization and restabilization at the sensorimotor synapse in Aplysia. Proc. Natl. Acad. Sci. U.S.A. 109, 14200-14205. doi: 10.1073/pnas.1211997109

Lee, S. K., and Hollenbeck, P. J. (2003). Organization and translation of mRNA in sympathetic axons. J. Cell. Sci. 116, 4467-4478. doi: 10.1242/jcs.00745

Lewis, T. L. Jr., Mao, T., and Arnold, D. B. (2011). A role for myosin VI in the localization of axonal proteins. PLoS Biol. 9:e1001021. doi: 10.1371/journal.pbio.1001021

Lopez-Salon, M., Alonso, M., Vianna, M. R. M., Viola, H., Souza, T. M. E., Izquierdo, I., et al. (2001). The ubiquitin proteasome cascade is required for mammalian long-term memory formation. Eur. J. Neurosci. 14, 1820-1826. doi: 10.1046/j.0953-816x.2001.01806.x

Lynch, G., and Baudry, M. (1984). The biochemistry of memory: a new and specific hypothesis. Science 224, 1057-1063. doi: 10.1126/science.6144182

Maggio, N., and Vlachos, A. (2014). Synaptic plasticity at the interface of health and disease: new insights on the role of endoplasmic reticulum intracellular calcium stores. Neuroscience doi: 10.1016/j.neuroscience.2014.09.041 [Epub ahead of print].

Martin, S. J., Grimwood, P. D., and Morris, R. G. (2000). Synaptic plasticity and memory: an evaluation of the hypothesis. Annu. Rev. Neurosci. 23, 649-711. doi 10.1146/annurev.neuro.23.1.649

Martin, S. J., and Morris, R. G. (2002). New life in an old idea: the synaptic plasticity and memory hypothesis revisited. Hippocampus 12, 609-636. doi: 10.1002/hipo.10107

Matsuda, S., Miura, E., Matsuda, K., Kakegawa, W., Kohda, K., Watanabe, M., et al. (2008). Accumulation of AMPA receptors in autophagosomes in neuronal axons lacking adaptor protein AP-4. Neuron 57, 730-745. doi 10.1016/j.neuron.2008.02.012

Matthies, H. (1989a). In search of cellular mechanisms of memory. Prog. Neurobiol. 32, 277-349. doi: 10.1016/0301-0082(89)90024-5

Matthies, H. (1989b). Neurobiological aspects of learning and memory. Annu. Rev. Psychol. 40, 381-404. doi: 10.1146/annurev.ps.40.020189.002121

McGaugh, J. L. (2000). Memory - a century of consolidation. Science 287, 248-251. doi: 10.1126/science.287.5451.248

McNair, K., Broad, J., Riedel, G., Davies, C. H., and Cobb, S. R. (2007). Global changes in the hippocampal proteome following exposure to an enriched environment. Neuroscience 145, 413-422. doi: 10.1016/j.neuroscience.2006.12.033

McNair, K., Davies, C. H., and Cobb, S. R. (2006). Plasticity-related regulation of the hippocampal proteome. Eur. J. Neurosci. 23, 575-580. doi: 10.1111/j.14609568.2005.04542.x
Meiri, N., and Rosenblum, K. (1998). Lateral ventricle injection of the protein synthesis inhibitor anisomycin impairs long-term memory in a spatial memory task. Brain Res. 789, 48-55. doi: 10.1016/S0006-8993(97)01528-X

Merhav, M., and Rosenblum, K. (2008). Facilitation of taste memory acquisition by experiencing previous novel taste is protein-synthesis dependent. Learn. Mem. 15, 501-507. doi: 10.1101/lm.986008

Meyer, D., Bonhoeffer, T., and Scheuss, V. (2014). Balance and stability of synaptic structures during synaptic plasticity. Neuron 82, 430-443. doi: 10.1016/j.neuron.2014.02.031

Mondin, M., Labrousse, V., Hosy, E., Heine, M., Tessier, B., Levet, F., et al. (2011). Neurexin-neuroligin adhesions capture surface-diffusing AMPA receptors through PSD-95 scaffolds. J. Neurosci. 31, 13500-13515. doi: 10.1523/JNEUROSCI.6439-10.2011

Monopoli, M. P., Raghnaill, M. N., Loscher, J. S., O’Sullivan, N. C., Pangalos,M. N., Ring, R. H., et al. (2011). Temporal proteomic profile of memory consolidation in the rat hippocampal dentate gyrus. Proteomics 11, 4189-4201. doi: 10.1002/pmic. 201100072

Nalavadi, V. C., Muddashetty, R. S., Gross, C., and Bassell, G. J. (2012). Dephosphorylation-induced ubiquitination and degradation of FMRP in dendrites: a role in immediate early mGluR-stimulated translation. J. Neurosci. 32, 2582-2587. doi: 10.1523/JNEUROSCI.5057-11.2012

Nguyen, P. V., Abel, T., and Kandel, E. R. (1994). Requirement of a critical period of transcription for induction of a late phase of LTP. Science 265, 1104-1107. doi: $10.1126 /$ science. 8066450

Novac, O., Guenier, A. S., and Pelletier, J. (2004). Inhibitors of protein synthesis identified by a high throughput multiplexed translation screen. Nucleic Acids Res. 32, 902-915. doi: 10.1093/nar/gkh235

Ohno, M. (2014). Roles of eIF2 $\alpha$ kinases in the pathogenesis of Alzheimer's disease. Front. Mol. Neurosci. 7:22. doi: 10.3389/fnmol.2014.00022

Ounallah-Saad, H., Sharma, V., Edry, E., and Rosenblum, K. (2014). Genetic or pharmacological reduction of PERK enhances cortical-dependent taste learning. J. Neurosci. 34, 14624-14632. doi: 10.1523/JNEUROSCI.2117-14.2014

Pathare, G. R., Nagy, I., Bohn, S., Unverdorben, P., Hubert, A., Korner, R., et al. (2012). The proteasomal subunit Rpn6 is a molecular clamp holding the core and regulatory subcomplexes together. Proc. Natl. Acad. Sci. U.S.A. 109, 149-154. doi: 10.1073/pnas. 1117648108

Pavitt, G. D., and Proud, C. G. (2009). Protein synthesis and its control in neuronal cells with a focus on vanishing white matter disease. Biochem. Soc. Trans. 37, 1298-1310. doi: 10.1042/BST0371298

Petrucci, T. C., Macioce, P., and Paggi, P. (1991). Axonal transport kinetics and posttranslational modification of synapsin I in mouse retinal ganglion cells. J. Neurosci. 11, 2938-2946.

Pielot, R., Smalla, K. H., Muller, A., Landgraf, P., Lehmann, A. C., Eisenschmidt, E., et al. (2012). Synprot: a database for proteins of detergent-resistant synaptic protein preparations. Front. Synaptic Neurosci. 4:1. doi: 10.3389/fnsyn.2012.00001

Price, J. C., Guan, S., Burlingame, A., Prusiner, S. B., and Ghaemmaghami, S. (2010). Analysis of proteome dynamics in the mouse brain. Proc. Natl. Acad. Sci. U.S.A. 107, 14508-14513. doi: 10.1073/pnas. 1006551107

Redondo, R. L., Okuno, H., Spooner, P. A., Frenguelli, B. G., Bito, H., and Morris, R. G. (2010). Synaptic tagging and capture: differential role of distinct calcium/calmodulin kinases in protein synthesis-dependent long-term potentiation. J. Neurosci. 30, 4981-4989. doi: 10.1523/JNEUROSCI.3140-09.2010

Reis, D. S., Jarome, T. J., and Helmstetter, F. J. (2013). Memory formation for trace fear conditioning requires ubiquitin-proteasome mediated protein degradation in the prefrontal cortex. Front. Behav. Neurosci. 7:150. doi: 10.3389/fnbeh.2013.00150

Renicke, C., Schuster, D., Usherenko, S., Essen, L. O., and Taxis, C. (2013). A LOV2 domain-based optogenetic tool to control protein degradation and cellular function. Chem. Biol. 20, 619-626. doi: 10.1016/j.chembiol.2013.03.005

Rosenblum, K., Futter, M., Jones, M., Hulme, E. C., and Bliss, T. V. (2000). ERKI/II regulation by the muscarinic acetylcholine receptors in neurons. J. Neurosci. 20, 977-985.

Rosenblum, K., Meiri, N., and Dudai, Y. (1993). Taste memory: the role of protein synthesis in gustatory cortex. Behav. Neural Biol. 59, 49-56. doi: 10.1016/01631047(93)91145-D

Saab, B. J., and Mansuy, I. M. (2014). Neuroepigenetics of memory formation and impairment: the role of microRNAs. Neuropharmacology 80, 61-69. doi: 10.1016/j.neuropharm.2014.01.026 
Saha, R. N., and Dudek, S. M. (2013). Splitting Hares and Tortoises: a classification of neuronal immediate early gene transcription based on poised RNA polymerase II. Neuroscience 247, 175-181. doi: 10.1016/j.neuroscience.2013.04.064

Scheel, H., and Hofmann, K. (2005). Prediction of a common structural scaffold for proteasome lid, COP9-signalosome and eIF3 complexes. BMC Bioinformatics 6:71. doi: $10.1186 / 1471-2105-6-71$

Schewe, D. M., and Aguirre-Ghiso, J. A. (2009). Inhibition of eIF2 $\alpha$ dephosphorylation maximizes bortezomib efficiency and eliminates quiescent multiple myeloma cells surviving proteasome inhibitor therapy. Cancer Res. 69, 1545-1552. doi: 10.1158/0008-5472.CAN-08-3858

Schott, G. D. (2011). Freud's Project and its diagram: anticipating the Hebbian synapse. J. Neurol. Neurosurg. Psychiatry 82, 122-125. doi: 10.1136/jnnp.2010.220400

Scott, D. A., Das, U., Tang, Y., and Roy, S. (2011). Mechanistic logic underlying the axonal transport of cytosolic proteins. Neuron 70, 441-454. doi 10.1016/j.neuron.2011.03.022

Segev, Y., Michaelson, D. M., and Rosenblum, K. (2013). ApoE epsilon4 is associated with eIF2alpha phosphorylation and impaired learning in young mice. Neurobiol. Aging 34, 863-872. doi: 10.1016/j.neurobiolaging.2012.06.020

Sha, Z., Brill, L. M., Cabrera, R., Kleifeld, O., Scheliga, J. S., Glickman, M. H., et al. (2009). The eIF3 interactome reveals the translasome, a supercomplex linking protein synthesis and degradation machineries. Mol. Cell 36, 141-152. doi: 10.1016/j.molcel.2009.09.026

Sharma, A. V., Nargang, F. E., and Dickson, C. T. (2012). Neurosilence: profound suppression of neural activity following intracerebral administration of the protein synthesis inhibitor anisomycin. J. Neurosci. 32, 2377-2387. doi 10.1523/JNEUROSCI.3543-11.2012

Sheng, M., and Hoogenraad, C. C. (2007). The postsynaptic architecture of excitatory synapses: a more quantitative view. Annu. Rev. Biochem. 76, 823-847. doi: 10.1146/annurev.biochem.76.060805.160029

Shin, S. M., Zhang, N., Hansen, J., Gerges, N. Z., Pak, D. T., Sheng, M., et al. (2012). GKAP orchestrates activity-dependent postsynaptic protein remodeling and homeostatic scaling. Nat. Neurosci. 15, 1655-1666. doi: 10.1038/nn.3259

Sidorov, M. S., Auerbach, B. D., and Bear, M. F. (2013). Fragile X mental retardation protein and synaptic plasticity. Mol. Brain 6, 15. doi: 10.1186/1756-6606-6-15

Silverman, M. A., Kaech, S., Jareb, M., Burack, M. A., Vogt, L., Sonderegger, P., et al. (2001). Sorting and directed transport of membrane proteins during development of hippocampal neurons in culture. Proc. Natl. Acad. Sci. U.S.A. 98, 7051-7057. doi: 10.1073/pnas.111146198

Song, J., Irwin, J., and Dean, C. (2013). Remembering the prolonged cold of winter. Curr. Biol. 23, R807-R811. doi: 10.1016/j.cub.2013.07.027

Spacek, J., and Harris, K. M. (1997). Three-dimensional organization of smooth endoplasmic reticulum in hippocampal CA1 dendrites and dendritic spines of the immature and mature rat. J. Neurosci. 17, 190-203.

Stock, J. B., and Zhang, S. (2013). The biochemistry of memory. Curr. Biol. 23, R741-R745. doi: 10.1016/j.cub.2013.08.011

Su, X., Lin, Z., and Lin, H. (2013). The biosynthesis and biological function of diphthamide. Crit. Rev. Biochem. Mol. Biol. 48, 515-521. doi: 10.3109/10409238.2013.831023

Suo, J., Snider, S. J., Mills, G. B., Creighton, C. J., Chen, A. C., Schiff, R., et al. (2011). Int6 regulates both proteasomal degradation and translation initiation and is critical for proper formation of acini by human mammary epithelium. Oncogene 30, 724-736. doi: 10.1038/onc.2010.445

Sutter, B. M., Wu, X., Laxman, S., and Tu, B. P. (2013). Methionine inhibits autophagy and promotes growth by inducing the SAM-responsive methylation of PP2A. Cell 154, 403-415. doi: 10.1016/j.cell.2013.06.041

Tang, Y., Scott, D., Das, U., Gitler, D., Ganguly, A., and Roy, S. (2013). Fast vesicle transport is required for the slow axonal transport of synapsin. J. Neurosci. 33, 15362-15375. doi: 10.1523/JNEUROSCI.1148-13.2013

Tang, Z., Xing, F., Chen, D., Yu, Y., Yu, C., Di, J., et al. (2012). In vivo toxicological evaluation of Anisomycin. Toxicol. Lett. 208, 1-11. doi: 10.1016/j.toxlet.2011.10.001

Thompson, K. R., Otis, K. O., Chen, D. Y., Zhao, Y., O’Dell, T. J., and Martin, K. C. (2004). Synapse to nucleus signaling during long-term synaptic plasticity; a role for the classical active nuclear import pathway. Neuron 44, 997-1009.

Toyama, B. H., Savas, J. N., Park, S. K., Harris, M. S., Ingolia, N. T., Yates, J. R., et al. (2013). Identification of long-lived proteins reveals exceptional stability of essential cellular structures. Cell 154, 971-982. doi: 10.1016/j.cell.2013.07.037
Trinidad, J. C., Thalhammer, A., Burlingame, A. L., and Schoepfer, R. (2013). Activity-dependent protein dynamics define interconnected cores of co-regulated postsynaptic proteins. Mol. Cell. Proteomics 12, 29-41. doi: 10.1074/mcp.M112.019976

Tsuriel, S., Geva, R., Zamorano, P., Dresbach, T., Boeckers, T., Gundelfinger, E. D., et al. (2006). Local sharing as a predominant determinant of synaptic matrix molecular dynamics. PLoS Biol. 4:e271. doi: 10.1371/journal.pbio.0040271

Vale, R. D. (2003). The molecular motor toolbox for intracellular transport. Cell 112, 467-480. doi: 10.1016/S0092-8674(03)00111-9

Vallee, R. B., and Bloom, G. S. (1991). Mechanisms of fast and slow axonal transport. Annu. Rev. Neurosci. 14, 59-92. doi: 10.1146/annurev.ne.14.030191.000423

Villers, A., Godaux, E., and Ris, L. (2012). Long-lasting LTP requires neither repeated trains for its induction nor protein synthesis for its development. PLOS ONE 7:e40823. doi: 10.1371/journal.pone.0040823

Waites, C. L., Leal-Ortiz, S. A., Okerlund, N., Dalke, H., Fejtova, A., Altrock, W. D., etal. (2013). Bassoon and Piccolo maintain synapse integrity by regulating protein ubiquitination and degradation. EMBO J. 32, 954-969. doi: 10.1038/emboj.2013.27

West, A. E., and Greenberg, M. E. (2011). Neuronal activity-regulated gene transcription in synapse development and cognitive function. Cold Spring Harb. Perspect. Biol. 3, pii: a005744. doi: 10.1101/cshperspect.a005744

Wiseman, S. L., Shimizu, Y., Palfrey, C., and Nairn, A. C. (2013). Proteasomal degradation of eukaryotic elongation factor-2 kinase (EF2K) is regulated by cAMP-PKA signaling and the SCFbetaTRCP ubiquitin E3 ligase. J. Biol. Chem. 288, 17803-17811. doi: 10.1074/jbc.M113.477182

Woehlbier, U., and Hetz, C. (2011). Modulating stress responses by the UPRosome: a matter of life and death. Trends Biochem. Sci. 36, 329-337. doi: 10.1016/j.tibs.2011.03.001

Wu, L., Luo, N., Zhao, H. R., Gao, Q., Lu, J., Pan, Y., et al. (2014). Salubrinal protects against rotenone-induced SH-SY5Y cell death via ATF4-parkin pathway. Brain Res. 1549, 52-62. doi: 10.1016/j.brainres.2014.01.003

Wyneken, U., Smalla, K. H., Marengo, J. J., Soto, D., de la Cerda, A., Tischmeyer, W., et al. (2001). Kainate-induced seizures alter protein composition and $N$-methylD-aspartate receptor function of rat forebrain postsynaptic densities. Neuroscience 102, 65-74. doi: 10.1016/S0306-4522(00)00469-3

Yao, I., Takagi, H., Ageta, H., Kahyo, T., Sato, S., Hatanaka, K., et al. (2007). SCRAPPER-dependent ubiquitination of active zone protein RIM1 regulates synaptic vesicle release. Cell 130, 943-957. doi: 10.1016/j.cell.2007.06.052

Yoon, B. C., Jung, H., Dwivedy, A., O’Hare, C. M., Zivraj, K. H., and Holt, C. E. (2012). Local translation of extranuclear lamin B promotes axon maintenance. Cell 148, 752-764. doi: 10.1016/j.cell.2011.11.064

Zhai, S., Ark, E. D., Parra-Bueno, P., and Yasuda, R. (2013). Long-distance integration of nuclear ERK signaling triggered by activation of a few dendritic spines. Science 342, 1107-1111. doi: 10.1126/science.1245622

Zhang, L., Ebenezer, P. J., Dasuri, K., Bruce-Keller, A. J., Fernandez-Kim, S. O., Liu, Y. et al. (2010). Activation of PERK kinase in neural cells by proteasome inhibitor treatment. J. Neurochem. 112, 238-245. doi: 10.1111/j.1471-4159.2009.06448.x

Ziv, N. E., and Fisher-Lavie, A. (2014). Presynaptic and postsynaptic scaffolds: dynamics fast and slow. Neuroscientist 439-452. doi: 10.1177/10738584145 23321

Conflict of Interest Statement: The authors declare that the research was conducted in the absence of any commercial or financial relationships that could be construed as a potential conflict of interest.

Received: 14 September 2014; accepted: 24 October 2014; published online: 12 November 2014.

Citation: Rosenberg T, Gal-Ben-Ari S, Dieterich DC, Kreutz MR, Ziv NE, Gundelfinger $E D$ and Rosenblum $K$ (2014) The roles of protein expression in synaptic plasticity and memory consolidation. Front. Mol. Neurosci. 7:86. doi: 10.3389/fnmol.2014.00086 This article was submitted to the journal Frontiers in Molecular Neuroscience. Copyright $\odot 2014$ Rosenberg, Gal-Ben-Ari, Dieterich, Kreutz, Ziv, Gundelfinger and Rosenblum. This is an open-access article distributed under the terms of the Creative Commons Attribution License (CC BY). The use, distribution or reproduction in other forums is permitted, provided the original author(s) or licensor are credited and that the original publication in this journal is cited, in accordance with accepted academic practice. No use, distribution or reproduction is permitted which does not comply with these terms. 